\title{
Impactos de la explotación de reservorios no convencionales de hidrocarburos sobre la actividad industrial y de servicios en el sistema de ciudades. El caso de la Cuenca Neuquina en la Patagonia Argentina
}

\author{
SUSANA GRACIELA LANDRISCINI \\ Universidad Nacional del Comahue - Buenos Aires - Argentina \\ OSVALDO PREISS \\ Universidad Nacional del Comahue - Buenos Aires - Argentina \\ LISANDRO ROBLES \\ Universidad Nacional de General Sarmiento/ Universidad Nacional del Comahue - Buenos Aires - Argentina
}

\begin{abstract}
Resumen
El presente trabajo exponeavances de conocimiento acerca dealgunosimpactos territoriales, dela exploracióny explotación de hidrocarburos de reservorios no convencionales en la Cuenca Neuquina Argentina. Se enfocan los cambios recientes en el sistema de ciudades de la Confluencia Neuquina y en las tramas de empresas que integran la cadena de valor. Ellos se extienden asimismo a localidades rionegrinas asentadas en la Cuenca, extendida hasta el sur de la provincia de Mendoza y el oeste de las provincias de la Pampa y Río Negro. Se retoman debates teóricos sobre las funciones de las ciudades, el peso de la trayectoria y los fenómenos de aglomeración, los cambios que se generan como parte de redes y flujos en tiempos de la globalización; y las cuestiones de la gestión del conocimiento y las capacidades de innovación de las pequeñas y medianas empresas proveedoras de bienes y servicios a los hidrocarburos. Se revisan documentos, planes y programas públicos sobre la región y las relaciones proveedores/clientes en el upstream, y se reflexiona acerca de las tensiones que generan dichos procesos, y las perspectivas de transformación del sistema urbano regional en su actual fase de desarrollo. La evaluación de los cambios urbanos de las actividades relacionadas al upstream, y una amplia gama de servicios directos de distinta intensidad tecnológica, involucran factores regionales y locales en las distintas ciudades, acorde a su localización, funciones, trayectoria histórica regional y de las localidades, y sus posibilidades de integración y diversificación económica. En dicho sistema de organización, Neuquén capital es un centro abastecedor de servicios públicos y privados, sociales, personales y a empresas, de distinto grado de complejidad y alcance regional. En ella se asientan las bases de las empresas de mayor envergadura. Otras ciudades operan como centros de importancia media y atraen firmas pequeñas y medianas; y un conjunto de centros menores lo hacen como proveedores locales. Se aborda asimismo el rol de los parques industriales en el ordenamiento territorial y en el desenvolvimiento de la cadena hidrocarburífera.
\end{abstract}

Palabras claves: Sistema de ciudades. Cuenca Hidrocarburífera Neuquina. Ordenamiento territorial. Gestión del conocimiento e innovación en Pequeñas y Medianas Empresas. 
Impactos exploração de reservatórios de hidrocarbonetos não convencionais sobre a actividades
industrial e de servicios no sistema cidade: o caso da Bacia de Neuquen, na Patagônia Argentina

\title{
Resumo
}

O presente trabalho expõe avanços de conhecimento a respeito de alguns impactos territoriais, da exploração e exploração de hidrocarburos de reservorios não convencionais na Bacia Neuquina Argentina. Focam-se as mudanças recentes no sistema de cidades da Confluencia Neuquina e nas tramas de empresas que integram a corrente de valor. Esse impacto também se estende a localidades rionegrinas assentadas em Cuenca, estendidos ao sul da província de Mendoza e províncias ocidentais de La Pampa e Rio Negro. Retomam-se debates teóricos sobre as funções das cidades, o peso da trajetória e os fenômenos de aglomeração, as mudanças que se geram como parte de redes e fluxos em tempos da globalização; e as questões de capacidade de pequenas e médias empresas que compõem o sistema produtivo e institucional territorial de gestão do conhecimento e inovação. documentos, planos e programas sobre a região e as relações fornecedor / cliente no montante são revistos, e reflete sobre as tensões geradas por esses processos, e as perspectivas de transformação do sistema urbano regional em seu estágio atual de desenvolvimento. A avaliação das mudanças urbanas das atividades relacionadas ao upstream, e uma ampla faixa de serviços diretos de diferente intensidade tecnológica, envolvem fatores regionais e locais nas diferentes cidades, de acordo com a sua localização, funções, trajetória histórica regional e localidades, e seu potencial para integração e diversificação económica. Em tal sistema de organização, capital de Neuquén é um centro público provedor e privada, social, pessoal e profissional, de diferentes graus de serviços regionais complexidade e abrangência. Nela se assentam as bases das empresas de maior envergadura. Outras cidades operam como centros de importância média e atraem assinaturas pequenas e médias; e um conjunto de centros menores fazem-no como provedores locais. Aborda-se assim mesmo o papel dos parques industriais no ordenamento territorial e no desenvolvimiento da corrente hidrocarburífera

Palavras-chave: Sistema de cidades. Cuenca Hidrocarbonetos Neuquen. Ordenamento do território. Gestão do conhecimento e inovação nas Pequeñas e Medias Empresas.

Impacts of the exploitation of unconventional hydrocarbon reservoirs on industrial activity and services in the city system: the case of the Neuquen Basin in Patagonia Argentina

\begin{abstract}
This paper presents advances in knowledge about the impact of exploration and exploitation of hydrocarbons from unconventional reservoirs in Argentina Neuquen Basin. Recent changes focus on the system of cities Confluence Neuquen and frames companies that make up the value chain. Such impact also extends to settled rionegrinas localities in Cuenca, extended to the south of the province of Mendoza and western provinces of La Pampa and Rio Black. theoretical debates about the functions of cities, the weight of the trajectory and agglomeration phenomena, the changes that are generated as part of networks and flows in times of globalization are taken up again; and issues of knowledge management and innovation capabilities of small and medium enterprises that make up the territorial productive and institutional system. Documents, plans and programs on the region and the supplier / customer relationships in the upstream are reviewed, and reflects on the tensions generated by these processes, and the prospects for transforming the regional urban system in its current stage of development. The assessment of urban changes related activities upstream and a broad range of services of different technological intensity, involving regional and local factors in different cities, according to their location, functions, regional historical trajectory and localities, and its potential for integration and economic diversification. In such a system of organization, Neuquén capital is a center provider public and private, social, personal and business, of varying degrees of complexity and scope regional services. It bases the larger companies are based. Other cities operate as centers of medium importance and attract small and medium-sized firms; and a set of smaller centers do as local suppliers. The role of industrial parks are also addressed in land use planning and in the development of the hydrocarbon chain.
\end{abstract}

Keywords: System of cities. Cuenca Hydrocarbons Neuquen. Land management. knowledge management and innovation in Small and Medium Enterprises. 


\section{Introducción}

El presente artículo retoma avances de conocimiento, producto de investigaciones realizadas por los autores acerca de la exploración y explotación de los recursos naturales no renovables en la Cuenca Neuquina y los múltiples impactos generados en el territorio. La investigación se propone objetivos en dos líneas: por un lado, indagar acerca de los cambios que las actividades vinculadas al nuevo ciclo de los hidrocarburos de reservorios no convencionales generan en el territorio en términos de localización industrial e infraestructura; y por otro, los que se corresponden con procesos de aprendizaje al interior de las pequeñas y medianas empresas que integran el segundo eslabón de proveedores en la cadena de valor de los hidrocarburos en la Cuenca. Los estudios se han planteado interrogantes acerca de sila expansión en el upstream puede significar la posibilidad de conjugar de forma sostenible el crecimiento de las ciudades, el ordenamiento territorial y la integración de actividades de la cadena hidrocarburífera en el territorio de la provincia de Neuquén. Conectado con ello, y en el marco de la aglomeración de firmas, se ha indagado también acerca de los cambios que se producen en la gestión del conocimiento y la organización del trabajo en su interior, y hacia afuera de ellas, los vínculos que mantienen con el sistema regional de innovación, particularmente con los clientes y proveedores, y con las concesionarias y las empresas de operaciones especiales, responsables de la perforación y terminación de pozos no convencionales en pilotos y desarrollos masivos.

La Cuenca Hidrocarburífera Neuquina está ubicada en la Norpatagonia argentina. Comprende áreas del este de la provincia de Neuquén, del noroeste de la provincia de Río Negro, y del sur de las provincias de La Pampa y Mendoza. El sector neuquino cuenta con los mayores recursos y reservas no probadas técnicamente recuperables de hidrocarburos de reservorios no convencionales. Tales recursos involucran: 1) la formación geológica Vaca Muerta que se extiende en $30.000 \mathrm{~km} 2 ; 2$ ) la formación Los Molles, segunda en importancia, con una superficie de $15.913 \mathrm{~km} 2$, destacada en materia de gas; y 3) la formación Agrio, que abarca un área de $1.000 \mathrm{~km} 2$ en la zona norte de Neuquén en la que se obtuvo shale oil a $3.558 \mathrm{mt}$. de profundidad, y cuyas características y potencialidad deben ser estudiadas. (Ver mapas con referencia a la Cuenca Neuquina) 


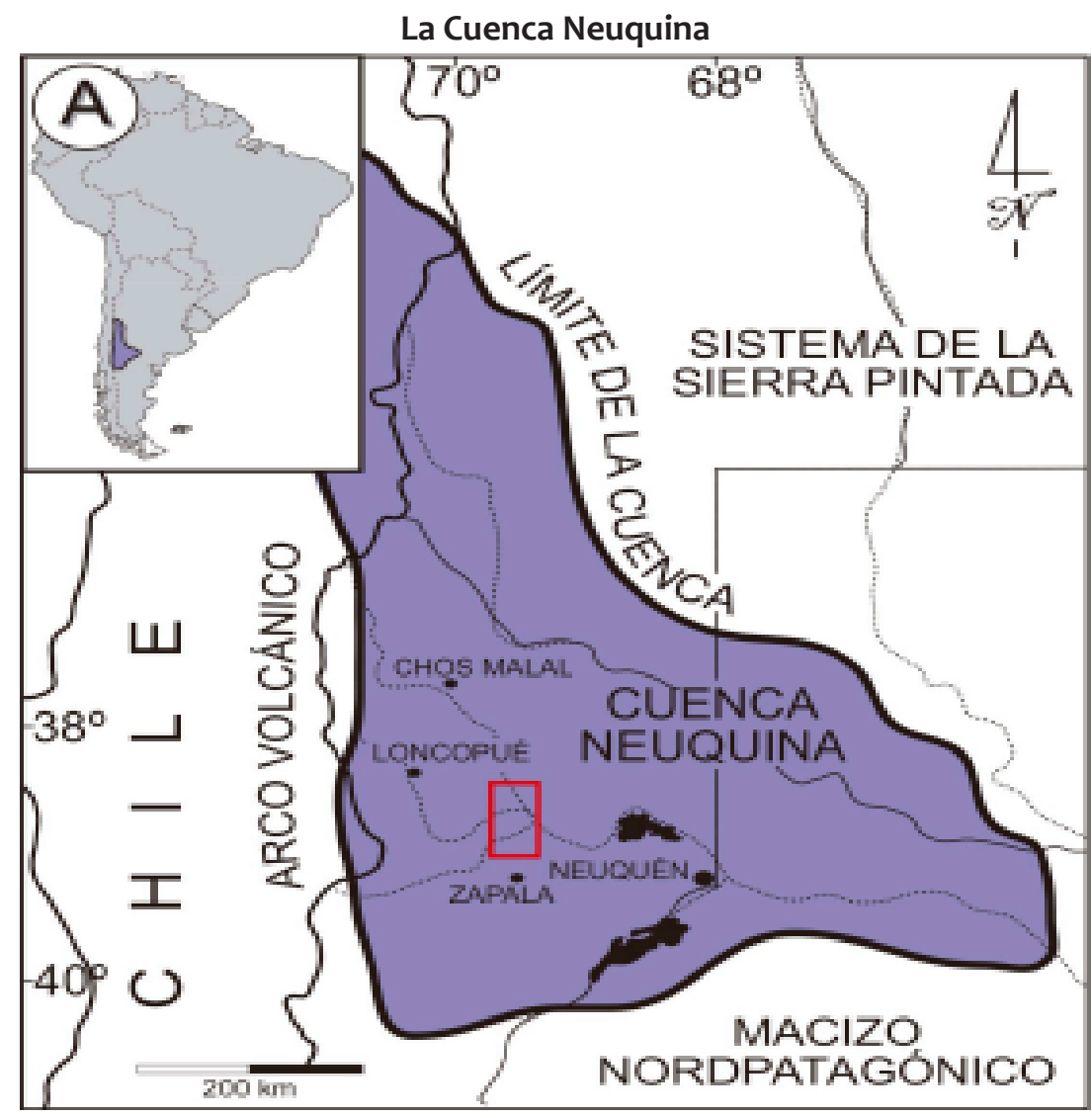

La formación geológica Vaca Muerta, y el sector del yacimiento Loma Campana

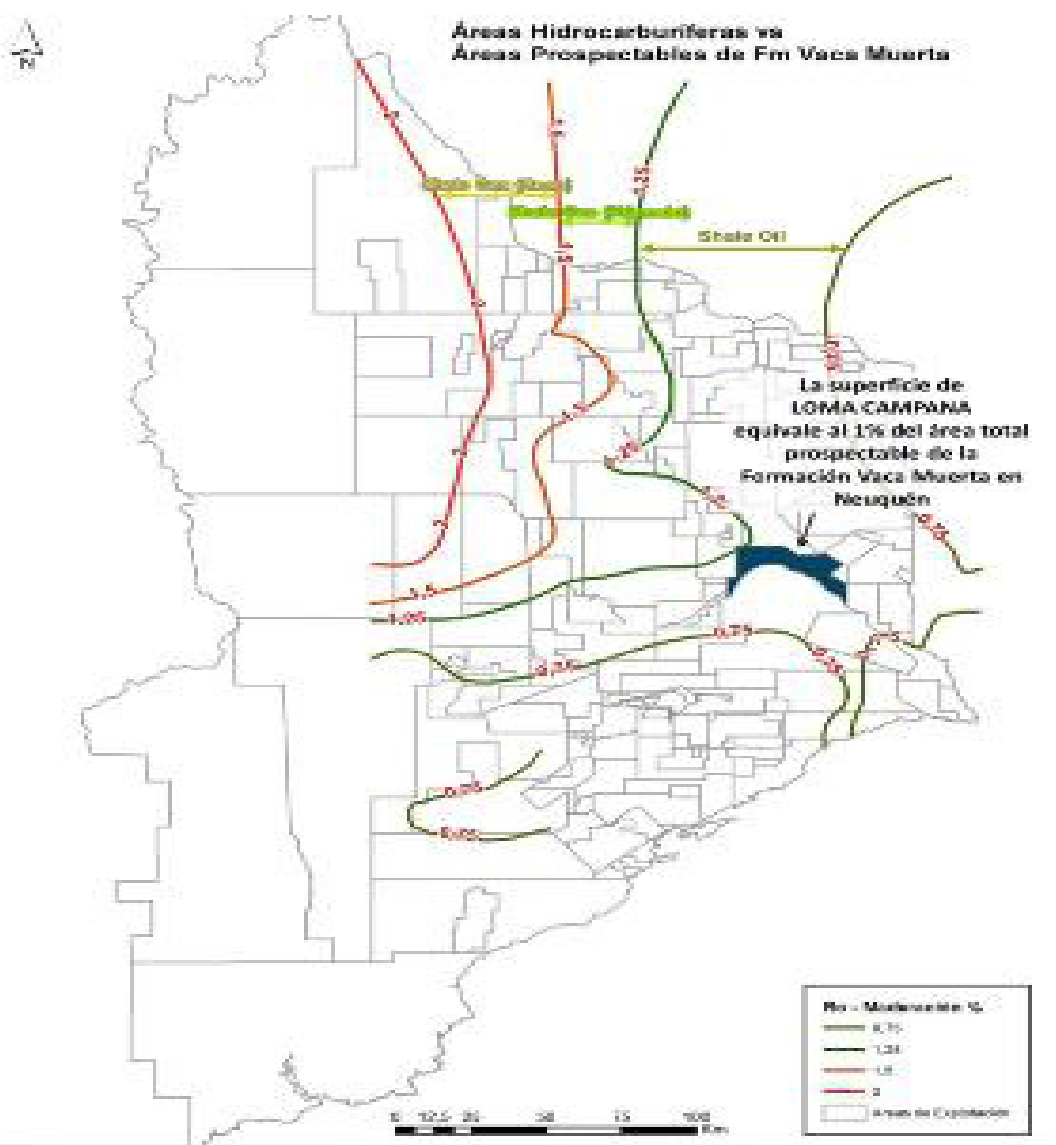




\section{La cuestión de la localización industrial: parques, áreas, y empresas}

De la revisión de la literatura sobre el tema en los aspectos teóricos y referidos a experiencias se evidencia que, en términos de creación de un ambiente favorable para la localización de nuevas empresas, uno de los instrumentos más tradicionales usados por los gobiernos locales para incentivar su radicación es el parque industrial. Sus beneficios se vinculan a la planificación territorial y a la política industrial, demandando de otras medidas que estimulen la innovación productiva y de gestión (Helmsing, 2006). En el caso de la actividad hidrocarburífera en la Cuenca Neuquina, los estudios de alcance público a escala provincial y local, han definido la necesidad de que su desarrollo no genere un crecimiento desordenado de las ciudades, resaltando la necesidad de contar con parques industriales para la radicación de las empresas, de modo que ello posibilite aprovechar los beneficios asociados a la provisión de bienes públicos y privados, y a la creación de una atmósfera industrial resultado de la concentración de firmas especializadas, en muchos casos de alto contenido tecnológico. Se busca potenciar la actividad económica provincial y local a partir de la radicación de empresas industriales y de servicios tradicionales y avanzados en los parques industriales, asociado ello al desarrollo nuevas configuraciones funcionales de las ciudades de la Confluencia. Dicha visión, responde -asimismo- a la necesidad de planificar el desarrollo técnico productivo y la aglomeración de las firmas, como expresión del ordenamiento territorial y desarrollo de las ciudades involucradas a partir de políticas específicas'.

En el complejo regional de actividades hidrocarburíferas, se cuentan un número aproximado de 500 empresas pequeñas y medianas contratistas y subcontratistas, muchas de las cuales se localizan o relocalizan en los parques industriales en expansión en las ciudades de la Confluencia Neuquina, de las cuales una importante proporción corresponden a las instaladas o renovadas en los últimos tres años. En función de ello, la investigación se ha propuesto avanzar en el análisis de un conjunto de aspectos asociados a su desenvolvimiento, en particular los referidos a la gestión del conocimiento y la organización del trabajo de un grupo de firmas que fueran seleccionadas por el Programa Sustenta de Desarrollo de Proveedores de la empresa nacional Yacimientos Petrolíferos Fiscales (YPF) para desarrollar técnicas, productos y servicios asociados a la exploración y producción no convencional, y que integran el segundo anillo de proveedores en la cadena de valor ${ }^{2}$. Dicho Programa, puesto en marcha por la empresa después de 2013 a través de un convenio con el Instituto Nacional de Tecnología Industrial, incluyó la realización de un diagnóstico técnico productivo de las firmas, la elaboración de propuestas para el mejoramiento de su gestión y la renovación de procesos, productos y servicios, y su puesta en marcha, como así también el avance en la certificación de normas internacionales del sector.

En ese marco, y como parte de los estudios llevados adelante referidos a las múltiples transformaciones operadas en la Cuenca Neuquina, Landriscini y Robles en 2015/2016 han investigado los
1 Conceptos extraídos de Landriscini, S. G., Preiss, O. y Avellá, B.; "El desarrollo de los hidrocarburos de reservorios no convencionales en la Cuenca Neuquina: Cambios en las ciudades, en su funcionalidad y vínculos; el rol de los parques industriales". Documento presentado a la XI Bienal del Coloquio de Transformaciones Territoriales, Universidad de la República. Salto, Uruguay, 27 al 29 de julio de 2016.

2 Landriscini, S. G. y Robles, L.; "Información, decisiones y participación en PyMEs de la Cuenca Hidrocarburífera Neuquina. El rol del dueño y del sistema regional de innovación". Documento presentado a la XXI Reunión de la Red PYME Mercosur, UNICEN, Tandil, 28 al 30 de septiembre de 2016. Proyecto de Vinculación Tecnológica. FAEA. UNComahue -YPF Regional Neuquén-INTI, Neuquén. 2015/16. 
cambios ocurridos en el sector hidrocarburífero a nivel nacional a partir de la renacionalización parcial de YPF y la exploración de los reservorios no convencionales, la creciente tendencia al uso de energías limpias, y la volatilidad de los precios internacionales del crudo, factores que exigen una mayor eficiencia operativa en las firmas, y estimulan la orientación al gas por sobre el petróleo, e inciden en forma directa e indirecta en la configuración y la dinámica de los centros urbanos de la Cuenca Neuquina. Sumado a ello, en lo estructural, ha resultado de interés conocer las problemáticas que evidencian dichas firmas localizadas en parques y áreas industriales en reconfiguración, en el nuevo ciclo de los hidrocarburos, ligadas a cuestiones de escala, al modo asimétrico de acoplamiento proveedor/cliente, a la introducción de los cambios técnicos que suponen las operaciones en los reservorios no convencionales, y al difícil acceso al financiamiento de inversiones. También ha interesado profundizar acerca de las ineficiencias operativas de las firmas pequeñas y medianas, identificadas en distintos estudios realizados sobre la cuestión (Kozulj y Lugones, 2007; Kozulj, 2011; Landriscini, 2015; Landriscini y Orlandini, 2014; Landriscini, et al, 2015; Neuman et al, 2012). Tales ineficiencias pueden inducir oportunidades de cambio, estimulando estrategias de asociación, de mejora organizativa, de diversificación, de escalamiento en la cadena de valor, o bien de supervivencia, para dichas firmas.

Relacionado con lo anterior, en el marco de la Economía del conocimiento, las nuevas tecnologías generan innovaciones disruptivas en diferentes sectores de la economía y la sociedad, los que también involucran a la industria de los hidrocarburos, considerada en los últimos tiempos como una industria madura. Es a partir de los desarrollos concretados en los Estados Unidos en materia de hidrocarburos de reservorios no convencionales (HRNC), que se viene operando una renovación tecnológica; se van imponiendo nuevos sistemas técnicos asociados a la perforación y terminación de pozos en la exploración, y nuevos procedimientos en la extracción, así como cambios en insumos, componentes y equipos, que plantean la necesidad de una nueva organización del trabajo en las firmas, y la toma de información técnico económica en tiempo real articulando logística, perforación y otras operaciones, lo que demanda capacitación específica del personal, y una rigurosa coordinación de procesos que se traduce en una nueva división del trabajo en el upstream. La nueva dinámica tiene implicancias territoriales diversas: se impulsan grandes inversiones de prospección con demandas específicas de infraestructura, y regulaciones ad hoc; al mismo tiempo, se ponen en marcha procesos de aprendizaje y desarrollo tecnológico localizados que demandan proximidad cognitiva e institucional y conectividad; una nueva logística y aglomeración de las empresas junto a centros de servicios, y la evaluación y prevención del impacto ambiental de las fracturas hidráulicas.

Considerando ese escenario, y los estudios de localización industrial, en el marco del proyecto de investigación se ha indagado acerca de las rutinas de las firmas pequeñas y medianas proveedoras de bienes y servicios especializados en la construcción de capacidades tecnológicas, en el desarrollo de nuevos procesos y productos y las 
mejoras de gestión internas, y en los vínculos externos, en productividad y en la competencia por la captación de clientes. En la cuestión, los aspectos particulares enfocados en la investigación han sido: (i) el rol del o los socios gerentes; (ii) la gestión de la información y el proceso de toma de decisiones; y (iii) las externalidades del entorno. De estos tres ejes temáticos se derivaron las siguientes preguntas de investigación en relación al proceso de cambios que enfrentan las firmas pequeñas y medianas del sector: 1) ¿En qué medida influye el papel del dueño y su trayectoria previa en el desenvolvimiento posterior de la empresa?; 2) ¿Cómo utiliza la empresa la información para tomar decisiones relativas al proceso y al mediano/largo plazo; y qué grado de participación tienen los empleados en ello?; 3) Qué estrategias horizontales se ponen en marcha en las firmas en la construcción de conocimiento y la implementación de mejoras productivas?; iv) ¿Cómo aprovechan las firmas las externalidades de su entorno? ¿Gestan experiencias asociativas horizontales o verticales?

\section{Marco teórico de referencia: ciudades, regiones, pequeñas y medianas empresas e innovación}

El enfoque teórico adoptado procura conjugar diversas vertientes del análisis económico: la literatura evolucionista sobre trayectorias e innovación, la temática del desarrollo regional y urbano, y en ella la consideración de las economías de aglomeración asociadas a la "atmósfera industrial", y las ventajas que la proximidad representa en términos de construcción de capacidades productivas, tecnológicas, institucionales y de inversión en las empresas y el territorio. Su finalidad es indagar sobre las perspectivas que se abren a partir de la posibilidad de unir estas líneas de investigación en lo que respecta al estudio de la evolución y posibilidades futuras de las regiones y ciudades en el marco del desarrollo de los recursos hidrocarburíferos de reservorios no convencionales localizados en la Cuenca Neuquina. En este sentido, se adopta el concepto de "path dependence" (dependencia de la trayectoria), utilizado frecuentemente en las teorías evolucionistas a partir de su aplicación por Arthur y David (2006) en estudios de evolución tecnológica, y luego ampliado a otros campos de la teoría económica, incluyendo la economía regional y urbana. Paul David (2006) desarrolla una crítica a la economía neoclásica incorporando la dimensión histórica en el estudio de los fenómenos del cambio económico; en esa línea, el concepto de "path dependence" destaca la importancia del contexto, la contingencia y la historia en los procesos de desarrollo económico. Esta visión dinámica de la evolución económica difiere de la tradición neoclásica de la economía, que en su forma más simple da por sentado que sólo existe un punto de equilibrio al que se puede llegar, independientemente de las condiciones iniciales o de los eventos transitorios.

Por su parte, Hodgson (2002) desde la visión institucionalista postula la necesidad de considerar determinantes históricos y/o geográficos en las teorías de la dinámica económica, lo que permite 
asociar el tiempo y el espacio en el análisis de los procesos económicos. En una línea similar, Martin y Sunley (2007), afirman que la combinación de la dimensión histórica proveniente de la utilización del concepto de "path dependence" debería unirse a las especificidades locales, dando lugar a una teoría "place dependent" de la trayectoria de una ciudad o región. En este sentido, la existencia de un cluster, definido como un agrupamiento de empresas relacionadas a partir de su interacción en un sector específico de la actividad económica y en un determinado espacio geográfico, operará positivamente en la trayectoria de una ciudad o región en la medida que las empresas puedan usufructuar los cuatro tipos de economías de localización que explican las ventajas derivadas de la concentración espacial de empresas según Lagerholm and Malmberg, 2009. Ellas son:

a) los beneficios derivados de la posibilidad de compartir los costos de ciertos recursos colectivos entre las firmas y otros tipos de bienes colectivos de la industria particular;

b) la reducción de costos de transacción entre las empresas localizadas en un mismo espacio, en tanto la proximidad permite además fortalecer la comunicación y la relación entre empresas, y facilita la desintegración vertical intra-firma de ciertas operaciones a favor de una integración al interior del cluster;

c) la concentración de firmas de un sector y de actividades relacionadas, de la que resulta la creación de un mercado de trabajo especializado; y

d) la circulación de conocimiento y aprendizaje localizado, facilitando la difusión de saberes y prácticas, el intercambio de experiencias, y la adopción de tecnologías e innovaciones.

De verificarse que las empresas pueden usufructuar estas ventajas devenidas de su localización conjunta, el cluster se constituirá en un polo de atracción para la instalación de nuevas empresas, pudiendo conducir al reforzamiento de una determinada trayectoria en la base económica urbana. Contrariamente, de no verificarse el comportamiento dinámico derivado de los factores anteriores, o existir bloqueos a la entrada de firmas, el cluster de empresas puede derivar en estancamiento, retraso tecnológico y falta de dinamismo innovador (Poma, 2000).

Las economías de localización operan al interior del cluster a partir de determinadas funciones que pueden alcanzar las ciudades donde el conjunto de empresas están localizadas, pero el agrupamiento puede también beneficiarse por las economías de urbanización. Camagni (2005) las define como "externalidades que se manifiestan en un ambiente urbano, dirigidas indistintamente a todas las actividades económicas y ya no específicas de sectores productivos concretos". Distingue entre ellas tres grandes categorías: a) las que nacen de la intervención del sector público en la ciudad: inversión en bienes públicos; b) las que derivan de la naturaleza de gran mercado de la ciudad; y c) las que se originan en la naturaleza de la ciudad como incubadora de factores productivos y de mercado de los insumos de producción. Por su parte, Hildreth argumenta que los servicios avanzados a la producción, y la generación de nuevo conocimiento productivo requieren de la existencia de 
economías de urbanización, pero por sobre todo de las capacidades locales para aprovecharlas (Gorenstein et al, 2012).

Desde las políticas públicas, las ciudades han intentado construir factores de atracción de empresas que refuercen o renueven su trayectoria económica a partir de la generación de economías de localización. En este sentido, entendiendo que el concepto de "path dependence" no puede interpretarse como una condición unívoca de la evolución futura de una ciudad, existen distintos factores que pueden dar lugar a una renovación de la trayectoria económica de una ciudad, basada en la integración de un nuevo sector clave a la base económica urbana o en la potenciación de un cluster de empresas ya existente. Se evidencia en este contexto, que la idea de dependencia de la trayectoria debe combinarse con la posibilidad de que un nuevo escenario regional/local en la Confluencia Neuquina, que se extiende a las ciudades rionegrinas más próximas, signifique para algunas ciudades la posibilidad de radicar un nuevo cluster de firmas relacionadas con la actividad hidrocarburífera (o una mayor integración y expansión de las ya existentes, o su diversificación relacionada), que si bien muestra tradición en la región, no se encuentra igualmente distribuida en el espacio regional, presentando fuertes anclajes en determinadas localidades y escasa relevancia en otras.

En términos de creación de un ambiente favorable para la localización de nuevas empresas, el parque industrial constituye una alternativa de ordenamiento, al tiempo que puede generar sinergia entre las firmas instaladas y un mejor aprovechamiento de insumos, recursos humanos y financieros, infraestructura, servicios, etc. ${ }^{3}$. Se extrae de estudios disponibles sobre organización industrial, (Briano et al, 2003, Garay, 1995; Gatto, 1990) que los beneficios de un Parque Industrial (PI) pueden ser de cuatro tipos:

i) los que refieren a la planificación espacial y urbana;

ii) los que devienen de un menor costo relativo en la provisión de servicios a empresas aglomeradas, comparado con otras localizaciones o soluciones individuales;

iii) los que se asocian a las economías de aglomeración y externalidades positivas;

iv) los que refieren a la perspectiva más general de la política industrial para la zona, región y el país.

Si bien la creación de una infraestructura física acorde no garantiza por sí sola la posibilidad de constituir un factor de atracción para la localización de empresas, en el contexto de la expansión de la actividad de un conjunto de empresas relacionadas en un ámbito regional y de los servicios avanzados a ellas, podrá generar economías de localización y sinergias entre las firmas que resulten en un reforzamiento o renovación de la base económica de la ciudad.

Las investigaciones realizadas en los últimos años en el campo de la geografía industrial, la economía internacional y la llamada "nueva geografía económica", muestran con claridad que la concentración de empresas en un determinado territorio puede generar efectos positivos sobre las empresas allí localizadas. Por caso, las transformaciones económicas recientes operadas en las regiones
3 Existen tres tipos de aglomeraciones urbanas planificadas: Parque industrial ( $\mathrm{Pl}$ ) es un terreno urbanizado y subdividido en parcelas, dotado de carreteras, medios de transporte y servicios públicos, que cuenta o no con fábricas construidas, que puede tener servicios e instalaciones o no, y que está destinado al uso de una comunidad de firmas industriales. - El área industrial es un terreno mejorado, dividido en parcelas con miras a la instalación de industrias; y - La zona industrial es un solar reservado para uso industrial. 
metropolitanas, suponen importantes cambios que involucran la división territorial del trabajo y las pautas de localización de las empresas, el dinamismo y la organización espacial de las diferentes actividades, empleos y funciones, con evidentes efectos sobre la forma urbana (Méndez, 2007). Las razones del mejor desempeño de las empresas concentradas en un territorio se derivan de las "economías de aglomeración"; en este caso las economías de localización que se generan al interior de la industria o sector, fruto de bienes colectivos que aumentan la competitividad de las empresas. A ello se agregan los beneficios que se asocian a las cuestiones culturales e históricosociales como el sentimiento de pertenencia de los actores territoriales que identifican el bienestar del territorio con el buen desempeño del sector, y, estrechamente vinculados con este sentimiento de pertenencia, los efectos benéficos de una fluida comunicación entre los actores locales, en el sentido de crear el efecto positivo de lo que A. Marshall a fines del siglo XIX llamó "atmósfera industrial". Dicho concepto actuaba como variable explicativa clave del buen desempeño de los distritos industriales ingleses de aquella época. A ello se agregan las consideraciones sobre los beneficios de la proximidad en materia de desarrollo de vínculos para el conocimiento expuestos por Becattini, 2002; Campolina Diniz y Crocco, 2006; Yoguel, 2000; 2001 y 2007, Torres, 2004, Maillat, 1994, entre otros autores.

El estudio de las pequeñas y medianas proveedoras de bienes y servicios especializados a los núcleos empresarios de los hidrocarburos en la Cuenca Neuquina, además de incorporar la cuestión de la trayectoria de las empresas, de sus titulares y de los planteles de trabajadores en el análisis de los procesos de transformación, recupera los enfoques sobre la gestión de la información y la organización del trabajo que plantean la importancia de las formas horizontales y participativas de construcción del conocimiento y la toma de decisiones en las firmas, en contraste con los modos tayloristas de organización.

Como fuera señalado precedentemente, el enfoque económico evolucionista busca identificar las reglas que rigen la transformación económica, teniendo en cuenta la complejidad en las interacciones de las dinámicas micro, meso y macroeconómicas. Desde esta visión, la innovación y el cambio tecnológico son considerados factores claves para explicar el crecimiento y la transformación económica" (Barletta et al, 2014, p. 11). En referencia a los comportamientos de las firmas, esta corriente identifica tres tipos de rutinas: (i) operativas; (ii) de modificación y (iii) de búsqueda de alternativas para introducir mejoras y desarrollar nuevas ventajas competitivas. De ello se deriva el concepto de capacidades dinámicas de las firmas. La relación entre los conceptos de capacidades tecnológicas y gestión del conocimiento es evidente si se considera que "la capacidad de crear, integrar, transferir y utilizar conocimiento en una forma continua apuntala las capacidades de la firma y sus ventajas competitivas" (Easterby-Smith \& Prieto, 2007, p. 235). Adicionalmente, existe cierto consenso en la literatura heterodoxa acerca del rol de las pequeñas y medianas empresas en la economía, especialmente a partir de los estudios de los Distritos Industriales Italianos (Becattini, 2002; Dini y Stumpo, 2011; Ferraro y Stumpo, 2010), 
la valorización de la flexibilidad en las empresas (Teece \& Pisano, 1994), y su impacto sobre el empleo y la innovación (Kantis, et al 2011).

A partir de lo anterior, se exploraron en la investigación las estrategias de gestión del conocimiento en grupos de pequeñas y medianas proveedoras en la Cuenca Neuquina, cuestión asociada a la organización del trabajo, el aprendizaje, los vínculos con el entorno y el papel del dueño o gerente como elemento central en la gestión de la firma, a fin de conocer los factores que inducen al éxito y los que retrasan la obtención de mejoras en la perfomance de las empresas, en su participación en los mercados, y en la relación con los clientes. La mejora en la gestión del conocimiento constituye un desafío relevante en la industria de los hidrocarburos, caracterizada como industria madura, y que al presente evidencia novedades resultantes del cambio técnico asociado a la exploración y explotación de reservorios no convencionales. Ello es clave con referencia a la cuestión de la generación y retención de los conocimientos por la tendencia al envejecimiento de la fuerza de trabajo, la complejidad del proceso productivo en yacimientos no convencionales (Di Sbroiavacca, 2013; Landriscini et al, 2015), la intensidad en el uso de conocimiento de esta industria en particular (Neto y Da Silva, 2012), y la necesidad de reducción de costos operativos frente a la volatilidad de los precios internacionales del crudo. Las pequeñas y medianas empresas de la cadena de hidrocarburos tienen la necesidad de generar nuevo conocimiento y de almacenarlo para su reutilización. Ello resulta tanto de sus propias operaciones, como también de las exigencias de los clientes, con los que se relacionan con débiles posiciones de negociación (Landriscini, 2012). En ese marco, Landriscini y Orlandini (2014) reflexionan en torno a las formas de co creación y difusión de conocimientos en redes formales e informales, resultado de la aglomeración y la trama de relaciones. Además, tal como indican Neuman et al (2012) en el Plan Estratégico para el Desarrollo de Proveedores de Bienes y Servicios de la Industria del Gas y del Petróleo, más del 90\% de las firmas proveedoras de bienes y servicios en la industria de hidrocarburos son pequeñas y medianas empresas de capitales nacionales.

Las pequeñas y medianas empresas de la cadena de hidrocarburos tienen la necesidad de generar nuevo conocimiento y de almacenarlo para su reutilización. Ello resulta tanto de sus propias operaciones, como también de las exigencias de los clientes, con los que se relacionan con débiles posiciones de negociación (Landriscini, 2012). En ese marco, Landriscini y Orlandini (2014) reflexionan en torno a las formas de co creación y difusión de conocimientos en redes formales e informales, resultado de la aglomeración y la trama de relaciones. Además, tal como indican Neuman et al (2012) en el Plan Estratégico para el Desarrollo de Proveedores de Bienes y Servicios de la Industria del Gas y del Petróleo, más del $90 \%$ de las firmas proveedoras de bienes y servicios en la industria de hidrocarburos son pequeñas y medianas empresas de capitales nacionales. ${ }^{4}$

En tanto tema central en la renovación industrial que vive la Cuenca Hidrocarburífera Neuquina, con implicancias en la localización y la creación de competencias en las tramas empresarias, cabe
4 Para 2010 el promedio de ocupados por firma era de 73 trabajadores. Por tanto, la temática analizada constituye una cuestión relevante para un alto porcentaje de las firmas proveedoras del sector, por lo general vinculadas directa o indirectamente al mercado externo a través de los distintos eslabones de la cadena. 
preguntarse entonces acerca de la posibilidad que tienen las firmas menores de desarrollar esfuerzos innovadores; y qué oportunidades y desafíos encuentran en este proceso de competencia evolutiva gestado en la Cuenca y de alcance global. La teoría ofrece respuestas diversas; y otras provienen de experiencias comparadas correspondientes a particulares momentos históricos, entornos institucionales específicos, niveles de desarrollo y tamaño de las economías, y a distintas ramas de actividad y modos de organización del trabajo y de gestión del conocimiento en las firmas.

Diniy Stumpo(2011)-por caso-en un reciente estudio que analiza políticas e instrumentos de apoyo para la innovación en las pequeñas y medianas empresas en América Latina, sostienen que la relación entre el tamaño de las firmas y su capacidad de innovación no es un tema nuevo para los economistas. Algunas de las hipótesis formuladas por Schumpeter $(1997,1972)$ haciendo referencia a las economías de escala y a la capacidad de las grandes empresas para controlar el mercado, e innovar en procesos, productos y gestión, Ilevan a pensar que las firmas de menor tamaño ocuparían exclusivamente posiciones marginales en la economía y que su aporte al proceso de innovación sería nulo o circunstancial. Sin embargo, con base en investigaciones empíricas, otros autores han llegado a diferentes resultados. Scherer (2000), por caso, ha sostenido que la innovación aumenta en proporción al tamaño de la empresa hasta un cierto punto, después del cual disminuye; mientras que Pavitt (1984) al estudiar empresas inglesas identificó una relación en U no invertida; y Soete (2009), en el caso de Estados Unidos descubrió una relación lineal entre tamaño e innovación. $Y$ es a partir de la década de 1990, que contribuciones inspiradas en el análisis de los aglomerados de empresas, sobre todo en las experiencias de los distritos industriales italianos (Pyke et al 1990; Pyke y Sengenberger 1992; Nadvi 1995; Humphrey y Schmitz 1996), impulsaron el desarrollo de un enfoque sistémico de la competitividad que interpreta la innovación como un proceso de aprendizaje, en el que pesa la trayectoria de los agentes en la que resulta determinante la interacción entre la empresa y su entorno productivo e institucional (Lundvall, 1985, 2005; Nelson \& Winter, 1982). Esta interpretación reconoce, por un lado, que no existe una sola vía óptima (one best way) para la generación de innovaciones; y, por otro, que la interpretación tradicional que relaciona de manera lineal la generación de innovaciones con las actividades de I+D, es una simplificación extrema de un proceso mucho más complejo (Dini y Stumpo, 2011).

De lo anterior, se desprenden dos consecuencias que orientaron la investigación:

1. se adoptó la definición amplia de innovación, considerando como esfuerzos innovadores a las mejoras organizativas y de gestión agregadas a las productivas, y no sólo los resultados; y

2. se ha reflexionado acerca de la validez o eficacia de las estrategias informales de innovación; éstas dependen del contexto en que operan las pequeñas y medianas del sector específico, de su configuración institucional, de su dinamismo técnico económico, etc., y pueden tener éxito en contextos en que la competitividad se 
basa en una capacidad de adaptación rápida de productos, procesos u organización, en un escenario caracterizado por una base cognitiva relativamente estable (Dini y Stumpo, 2011; Katz y Zamorano, 2011). firmas se desempeñan no sólo está relacionada al sector económico en que actúan, sino también al contexto empresarial-institucional. En este sentido, los sistemas productivos y de innovación locales pueden influir ya sea generando capacidades colectivas de análisis de las tendencias de los mercados y escenarios competitivos, y brindando o no estímulos para la apertura de los agentes y las relaciones hacia afuera, y para despertar su interés en la observación y la búsqueda de nuevas realidades y nuevas perspectivas. Eso depende tanto de estrategias colectivas explícitas que contemplen estas metas, como de valores y tradiciones acumuladas que caracterizan la cultura productiva y social de la comunidad considerada, y de las políticas públicas. Además, una serie de características de la comunidad local influencian las posibilidades de respuesta de parte de los actores locales. La capacidad cognitiva de los mismos depende de manera significativa de las características del sistema productivo territorial considerado y de la división del trabajo alcanzada entre las empresas que lo conforman y su trayectoria. En la medida en que en un sistema local se generan externalidades y procesos cooperativos de aprendizaje, sus integrantes podrán contar con activos que acrecientan sus capacidades competitivas. Para integrar los conocimientos individuales con los del entorno, disminuir la incertidumbre estratégica (Kline y Rosenberg, 1986), y potenciar los procesos de aprendizaje, las empresas requieren de un umbral mínimo de competencias que va aumentando a medida que los sistemas pierden virtuosidad (Yoguel et al, 2007). Por caso, las actividades en el sector hidrocarburos en el que predominan las tramas empresarias jerárquicas en las cadenas de valor, plantean fuertes exigencias a las firmas menores en materia de actualización tecnológica, certificación de normas de procesos y auditoría de productos, y en cuanto a flexibilidad, costos y tiempos de respuesta. De este modo, cuanto mayor es la "proximidad cognitiva" tanto más efectiva resulta la observación y más fácil la movilidad de los recursos humanos al interior del sistema productivo. A ello Boschma (2010) le agrega la "proximidad geográfica, organizacional, social, e institucional”. En cuanto a la capacidad de generación de conocimientos, señalan que este proceso es tanto más intenso cuanto más desarrollada es la división externa del trabajo (especialización).

En síntesis, la capacidad de un sistema productivo de absorber y difundir nuevos conocimientos tiene que ver, según Dini y Stumpo, con un conjunto de características de su estructura, entre las que destacan: el número de actores independientes que lo conforman; la intensidad de sus vínculos y de los mecanismos que facilitan su interacción; el modelo de división interna y externa del trabajo; y el nivel de proximidad cognitiva que se registra entre los integrantes del sistema considerado. (Dini y Stumpo, 2011) En tal sentido, consideran los autores que, es muy relevante el papel de las universidades generando densidad institucional para la investigación y desarrollo y la transferencia tecnológica, que coopere al desarrollo de innovaciones, 
mejoras de productividad y apropiación horizontal de resultados. En el caso de las cadenas de valor en las que reina un fuerte acoplamiento entre proveedores y clientes, aparecen consideraciones particulares que se vinculan a lo tecnológico: la posición de las pequeñas y medianas empresas en la cadena, la especificidad de los procesos y de los bienes y servicios, la circulación de información, la complementariedad, la asistencia postventa, y los aspectos económico-financieros, ligados a la estructura del mercado, al grado de asimetría en las relaciones y a las condiciones contractuales. (Pietrobelliy Rabellotti, 2004)Latin American and Caribbean countries should increase their competitiveness. Micro, small and medium enterprises may play a critical role to trigger the region/u2019s competitiveness, and government should support them. This study provides policy lessons and recommendations on how to support SME upgrading in the global market. The study analyzes the SME upgrading process in the context of clusters and value chains as well as in different economic sectors. The analysis is based on the collection of original data from twelve new clusters in Latin America, and on an extensive literature review of cluster studies. These cases are the largest selection available on which comparative exercises have been carried out. Based on the empirical analysis, the authors explain how small and medium enterprises located in clusters can innovate as a consequence of external economies and joint actions (collective efficiency Otros estudios amplían la unidad de análisis adoptando una visión de tramas empresarias en las cadenas globales de valor (Delfini, et al, 2007). En ellos se han enfocado los temas de la coordinación de los actores públicos y privados y los relativos a la generación y gestión de bienes o servicios competitivos, así como la distribución de ingresos (Anlló, et al 2009).

De acuerdo con los aportes de Lall (1992), las capacidades tecnológicas a nivel de un país se ordenan en tres categorías: inversión física, capital humano y esfuerzos tecnológicos. Este autor argumenta que las tres categorías son interdependientes, ya que si el capital físico se acumula sin las habilidades, o sin la tecnología necesaria para operarlo de modo eficiente, las capacidades tecnológicas nacionales no se desarrollarán de modo adecuado. Es decir que, la inversión en infraestructura como bien público como es el parque industrial, y la privada que se desarrolla en escala micro en la planta y equipos, es, en cierto sentido, una capacidad básica si ellos son necesarios para que exista la industria, pero lo más importante es la eficiencia con la cual se utiliza el capital instalado. En cuanto al capital humano, él incluye no sólo las habilidades generadas por la educación y la capacitación formales, sino también las que se desarrollan con la práctica y la experiencia en las actividades, y las capacidades heredadas, que ayudan al desarrollo tecnológico. La capacidad en esfuerzos tecnológicos se relaciona con la mano de obra especializada disponible para tareas técnicas, gastos en investigación y desarrollo formales, o innovaciones y patentes; capacitación formal e informal, y otros indicadores de éxito tecnológico (medido en resultados). Así, el trabajo cualificado y el capital físico son productivos sólo si se combinan con esfuerzos de las empresas productivas para asimilar y mejorar la tecnología relevante. Es por 
ello que la acumulación de capacidades tecnológicas supone procesos arriesgados e imprevisibles y demanda arreglos institucionales.

Por su parte, Bell y Pavitt (1992) señalan tres etapas en los procesos de acumulación de capacidades tecnológicas, lo que condiciona los procesos de mejora individual y colectiva de las firmas: en la primera, la tecnología es adoptada para incorporarla en nuevas instalaciones; en la segunda, se incrementa la eficiencia inicial y se modifica la tecnología adecuándose a los cambios en los mercados de insumos y productos; y en la tercera, las empresas pueden basarse en las capacidades ya adquiridas durante las dos etapas anteriores para introducir un cambio técnico más sustancial, modificando o sustituyendo los productos existentes; diversificando los materiales de insumo y producto o modificando las tecnologías usadas. Este proceso de acumulación de capacidades parte de una base mínima de conocimientos tecnológicos, por la cual las empresas son tecnológicamente inmaduras, pues aprenden y acumulan conocimientos con el paso del tiempo; y adquieren capacidades tecnológicas hasta estar preparadas para llevar a cabo actividades de innovación (Ortega Rangel, 2005; Dutrénit, 2003).

En los países en desarrollo se ha identificado una secuencia en el proceso de adquisición o desarrollo de capacidad tecnológica, la que puede resumirse en las siguientes etapas:

1. Identificar una oportunidad o un problema; 2. Explorar las soluciones tecnológicas posibles, seleccionar las más apropiadas y, si es necesario, negociar la adquisición del nuevo conocimiento tecnológico; 3. Operar la tecnología; 4. Adaptar la tecnología a las condiciones locales; 5 . Modificar la tecnología en respuesta a los cambios del entorno económico; 6. Modificar sustancialmente el proceso o el producto; y 7. Llevar a cabo I \& D internos de forma organizada y sistemática.

Esta diferenciación resulta de gran utilidad para abordar los procesos de mejora en las firmas, sus posibilidades y restricciones hacia adentro, y en materia de vinculación con el entorno en las pequeñas y medianas empresas desafiadas por cambios técnico productivos en sectores maduros como los hidrocarburos, y los asociados a ellos desde la metalmecánica y la electrónica, y por crecientes barreras a la entrada. (Ortega Rangel, 2005) Siguiendo esa literatura, la acumulación de capacidades tecnológicas de las empresas aporta mejoras en la competitividad de las mismas. Ello lleva a revisar el concepto de competitividad avanzando hacia una visión sistémica. En tal sentido, la corriente evolucionista señala como factor clave de la competitividad al factor tecnológico expresado en la capacidad de transformar insumos, incrementar la eficiencia en su uso, y crear productos y procesos de producción más complejos (Ortega Rangel, 2005).

La indagación acerca de las pequeñas y medianas empresas de la Cuenca Neuquina lleva a recuperar los aportes de Tudela y Garrido, que destacan la capacidad de este segmento de firmas para contribuir de manera flexible y con alto contenido tecnológico a la competitividad de los países desarrollados. Referido al caso de estas firmas en América Latina, tales autores señalan que ellas muestran un fuerte rezago en sus capacidades para desarrollar conductas competitivas con base en prácticas innovadoras. Ello ha estimulado a países de la región a 
implementar programas de apoyo a la mejora de estas firmas y sus agrupamientos innovadores como para lograr una mayor participación de las mismas en el desarrollo de los países, en su comercio exterior, etc. (Tudela y Garrido, 2015).

Un primer elemento relevante a destacar -según los autoresson las fortalezas de este tipo de empresas. Entre ellas destacan la mayor rapidez para diversificar su producción con menores costos asociados a ello y adecuar la mano de obra a las nuevas necesidades. Esto hace que tengan ventajas relativas de flexibilidad para lograr posicionamiento y competitividad en el mercado, y puedan responder de mejor manera a los desafíos de la globalización, la incorporación de nuevas tecnologías, los cambios organizacionales y el avance de los sistemas de información. Adicionalmente, señalan la importancia que tiene la presencia del propietario en la operación de los negocios. Ello se traduce en una fuerte concentración de la gestión normalmente a cargo del dueño, quien opera con estrategias relativamente intuitivas que permiten un proceso de toma de decisiones rápido.

Otro rasgo relevante es la baja especialización de los factores de producción con que operan, sistemas de información internos con pocos o ningún nivel jerárquico, y sistemas de información externos basados en una relación muy directa con clientes y proveedores. Es así que la mayoría de los estudios recientes sobre pequeñas y medianas empresas a nivel internacional, destacan la importancia de los beneficios de la innovación, la Gestión de la Calidad Total como enfoque de gestión y la formalización en las prácticas de gestión de la firma. Más allá de ello, la adopción de prácticas gerenciales en ese segmento de empresas varía mucho según el tamaño. Las unidades más pequeñas son las que más confían en las peculiares circunstancias de sus operaciones y en la habilidad de los líderes de la firma en algunas áreas del negocio, como ser: habilidades técnicas, relaciones personales con los clientes y proveedores, $y$ habilidad superior para comprar y vender.

A ello se agregan elementos en cuanto al estilo de gestión empresarial, de lo cual emergen los factores de heterogeneidad en el segmento. Las especificidades de ellas y de quienes las gestionan, en particular en América Latina, han hecho evidente la necesidad de formular políticas que refuercen la capacidad de gestión de este tipo de empresas, lo que ha llevado a pasar de las tradicionales más orientadas a los casos individuales, hacia una visión más comprensiva de las condiciones y necesidades en que operan estas firmas, y los desafíos que les representa innovar para competir desde un enfoque sistémico que reconozca los condicionantes del contexto para esa gestión. Además, como es sabido, en el caso de las pequeñas y medianas empresas el proceso de innovación se genera a través de canales distintos que los de la gran empresa, ya que en ellas el conocimiento tácito, los esfuerzos informales y las mejoras incrementales adquieren mayor relevancia en los procesos de aprendizaje, en comparación con las grandes empresas. Tales especificidades hacen que para impulsar la innovación estas firmas mejoren la capacidad de relacionarse con las grandes empresas, participen de redes productivas y establezcan vínculos con el entorno social y productivo local. Estas acciones parecieran tener 
mayor importancia para las pequeñas empresas que el incremento del gasto en investigación y desarrollo (Dini Stumpo, 2010).

En el caso de América Latina y el Caribe, Tudela y Garrido (2015) resaltan la situación de fuerte heterogeneidad y rezago de las pequeñas y medianas empresas en términos de desempeño. Las más dinámicas e innovadoras son relativamente pocas en la región, y las menos dinámicas requieren otro tipo de propuestas para lograr incrementos de productividad en lo que la vinculación con las universidades resulta de gran utilidad. En tal sentido, cabría facilitarles el introducir nuevas tecnologías, promover formas de colaboración con instituciones y otras firmas, participar en redes, etc. Ello les permitiría ir cambiando gradualmente sus modos de gestión y las prácticas empresariales. Según los autores, las universidades pueden crear centros de transferencia tecnológica que sirvan de puente entre ellas y las pequeñas y medianas empresas, cooperando a crear una atmósfera industrial renovada y a promover la conformación de agrupamientos productivos. La literatura sobre el tema y la experiencia internacional, señalan que la participación en estos agrupamientos genera notables ventajas para su desarrollo en cuanto a acceso a información relevante sobre tecnología, oportunidades de negocios y alianzas posibles, construcción de un capital territorial, fortalecimiento institucional, ganancia de escala y conocimiento, articulación insumo-producto, desarrollos conjuntos de procesos e infraestructura, de productos o mercados, de legislación a nivel territorial, etc. El impacto y las posibilidades de escalamiento de las firmas pequeñas y medianas se ven potenciadas si en esos agrupamientos productivos participan también las universidades, institutos o centros de investigación con sus recursos.

\section{Metodología}

La investigación en la que se inspira este artículo se inició en 2014 con revisión bibliográfica de documentos sobre políticas y proyectos provinciales sobre ordenamiento territorial y entrevistas a informantes calificados del complejo hidrocarburífero radicados en ciudades de la Cuenca Neuquina.

A posteriori, se realizó una búsqueda de literatura relativa a los temas que la aproximación inicial indicó como centrales en la cuestión de la localización industrial y en la gestión de proveedores pequeños y medianos de bienes y servicios especializados, y se seleccionó a algunos de ellos siguiendo la preselección del Programa Sustenta de Desarrollo de Proveedores de YPF. Se diseñaron cuestionarios de entrevistas en profundidad y se aplicaron en las empresas seleccionadas. Los mismos se incluyen como Anexo al final del presente artículo.

Con base en los conceptos recuperados de la bibliografía, se procedió a analizar la situación actual y proyectada de los parques industriales de tres ciudades de la provincia de Neuquén: Neuquén capital, Centenario y Añelo, las más impactadas por el nuevo escenario de desarrollo de los hidrocarburos de reservorios no convencionales. En dicho análisis, se puso énfasis en la cuestión de la función de las 
ciudades, así como en las nuevas modalidades de ocupación del suelo por parte de industrias y empresas de servicios, y en la previsión de obras y de operaciones de logística.

Como fuera señalado, se relevó un conjunto de empresas integradas al Programa Sustenta de Proveedores de YPF ejecutado en los años 2014 y 2015 de modo asociado al INTI sede Neuquén, en cuanto al plan de mejoras propuesto e instrumentado. El número total fueron 16 empresas asociadas a dicho Programa, y un número de 8 adicionales fueron consultadas por fuera del mismo como modo de contraste. En las incorporadas al Programa, como consta en los cuestionarios, se plantearon preguntas acerca de lo observado en los diagnósticos, en particular respecto a la gestión del conocimiento y los procesos de aprendizaje tecnológico en las firmas; la existencia o no de áreas específicas de investigación y desarrollo y de convenios o contratos con instituciones u otras empresas con ese fin; y acerca del tipo de capacitación del personal, el manejo de información y los procesos de toma de decisiones. Se avanzó en la búsqueda de explicaciones acerca del modo de gestión del conocimiento, y se trabajó en un modelo de análisis de la información obtenida, formulándose hipótesis centrales y auxiliares, algunas de las cuales fundamentan los interrogantes planteados en la investigación. La información de campo obtenida para cada empresa fue analizada buscando su consistencia, comparando los modos de operación en relación a la construcción de capacidades tecnológicas en las empresas dentro y fuera del Programa Sustenta, y a posteriori la información obtenida fue contrastada con los elementos proporcionados por la teoría. Se consultaron además experiencias de programas de desarrollo de proveedores de industrias metalmecánicas e hidrocarburíferas en América Latina. La producción de nuevo conocimiento se centró en el papel del dueño/gerente en la gestión de información y la toma de decisiones, en la organización del trabajo y la proyección de mejoras, y en los vínculos con el entorno científico tecnológico y empresario.

Posteriormente, se extrajeron conclusiones preliminares con relación a los cambios en curso en el sistema productivo territorial a partir del análisis de la situación observada en los parques industriales y ciudades, y en las empresas, y sobre las propuestas de mejoras y la evaluación de marcha de las acciones emprendidas en ese rumbo. A partir de la información obtenida, se retomó la reflexión teórica, y se buscó responder a las preguntas sugeridas, dando cuenta de los avances de conocimiento alcanzados.

\section{Neuquén: una ciudad intermedia integrada en la microregión en transformación}

En un mundo en el que se expande de continuo la urbanización, las ciudades medias se han convertido en un objeto de estudio particular, más allá del tamaño de su población, dado que enfrentan problemas y desafíos propios que las diferencian de las grandes metrópolis o ciudades globales, y que refieren a la descentralización de la producción, la capacidad innovativa de los agentes productivos 
y los gubernamentales, la identidad, la sinergia y las relaciones sociales dentro de los sistemas urbanos. Su estudio debe partir de las situaciones territoriales diferenciales que las involucran, las que son producto de factores estructurales del sistema económico social, y político institucional, que han marcado y marcan su trayectoria, y en los tiempos recientes, del impacto de la globalización, de las nuevas tecnologías y formas de organización del trabajo en las estructuras productivas, y del Estado, en relación a los marcos regulatorios sobre el uso de los recursos y los sistemas urbano regionales. Involucra -entonces- diversas dimensiones, distintas disciplinas, y múltiples esferas y escalas de análisis.

Neuquén capital, como otras ciudades medias argentinas, constituye un particular objeto de estudio en la temática del desarrollo urbano-regional. Su desenvolvimiento demográfico, socioeconómico y político institucional reciente, y las transformaciones ambientales derivadas de la apropiación y uso del suelo y el subsuelo, el agua y el paisaje, por un lado, y la instalación de población vulnerable en zonas de riesgo, vienen generando crecientes tensiones entre el Estado, el mercado y la sociedad civil. A ello se agrega en los últimos años el impacto del desarrollo hidrocarburífero asociado a la exploración y explotación de los recursos de reservorios no convencionales en la Cuenca Neuquina, y la política expansiva que ha llevado adelante YPF a partir de su renacionalización en mayo de 2012 orientada al autoabastecimiento energético y la sustitución de importaciones. Estos hechos, que se asocian además a la llegada de relevantes inversiones de compañías extranjeras líderes del sector, de más de U\$S 5.000 millones en 2015, vienen provocando cambios muy relevantes en la división regional del trabajo, en los sistemas productivos e institucionales locales, y en la dinámica de las empresas y los territorios, de los que emergen también conflictos ambientales. A partir de 2016, los cambios operados en la política macroeconómica y energética y en la gestión de YPF plantean nuevos interrogantes que se agregan a los que devienen de la volatilidad de los precios internacionales del petróleo y de las estrategias de las grandes operadoras respecto a sus planes de inversión, el aumento de la productividad y la reducción de costos. Ello conlleva ajustes de estructura y en los planteles de trabajadores, y pone en cuestión la sustentabilidad social y ambiental en la microregión conformada por las ciudades asentadas en la Cuenca Neuquina, como así también en las ciudades de otras cuencas hidrocarburíferas patagónicas.

A lo largo del tiempo, los regímenes económicos nacionales definieron rumbos particulares en las formas institucionales y en la ocupación del espacio. Quedó así configurado el territorio nacional a partir de las dinámicas productivas, el peso y el modo de acción de las inversiones extranjeras, las definiciones estatales en distintas jurisdicciones, y la dinámica poblacional y social. En las últimas décadas del siglo XX, la privatización de las empresas públicas, la desregulación del mercado de los hidrocarburos y de la tierra, junto a la primacía financiera de la economía y la flexibilización laboral, impactaron en la configuración urbano-regional en la Patagonia en general y en la zona Norte en particular, condicionando su desenvolvimiento, y su posicionamiento en el sistema urbano nacional. Del mismo modo, las 
transformaciones tecnológicas y de organización de la producción y el intercambio a nivel global, afectan al presente la economía regional y local y la configuración urbana, multiplicando las demandas sociales.

A partir del reciente desarrollo de los hidrocarburos de reservorios no convencionales en la Cuenca Neuquina, surgen nuevas problemáticas que se desenvuelven en los asentamientos productivos y humanos en la zona de la Confluencia, las que inciden en los procesos de consolidación, densificación y sub urbanización, y se traducen en fragmentación socio-territorial, déficit de servicios, y otras cuestiones resultantes de las distintas fases del crecimiento de Neuquén capital y las localidades de su entorno. La ciudad crece en población y ocupación, en la demanda de servicios y en la complejidad de sus funciones. Ello impacta en los municipios próximos que se ven compelidos a poner en marcha ordenamientos territoriales y elaborar códigos de uso del suelo, en el marco de la nueva división regional del trabajo. Muchas de las cuestiones señaladas son estudiadas dando lugar a informes técnicos específicos, y otras se abordan a partir de los proyectos públicos locales y provinciales. De ellas emergen planes urbanos, regulaciones, obras públicas y negociaciones con agentes privados y grupos sociales diversos, con municipios vecinos y con otras jurisdicciones. Pueden citarse también los espacios de consulta, diálogo y participación surgidos en el ámbito local. No obstante, la dinámica económica regional y local, los negocios inmobiliarios, los intereses divergentes entre actores productivos y rentistas, y la presión social por la vivienda, el hábitat y la provisión de servicios, han generado y generan de continuo una multiplicidad de conflictos sociales, económicos, ambientales, e institucionales entre jurisdicciones diversas y entre distintos grupos sociales y las operadoras. La resolución de los conflictos de intereses va con frecuencia por delante de la gestión pública; imponiéndose la dinámica de los hechos o del derecho privado sobre la del derecho público, el acuerdo social, la eficiencia económica, la racionalidad ambiental y la equidad social. Ello hace impostergable la puesta en marcha de un proceso de planificación microregional concertado que minimice los impactos negativos de la demanda de suelo urbano y servicios para las radicaciones de empresas y viviendas, que ordene la construcción de infraestructura y pueda dar respuesta a las múltiples implicancias que los procesos de cambio traen consigo.

En el nuevo escenario, la Confluencia -como área metropolitanay en particular Neuquén capital como ciudad intermedia, y Centenario y Añelo como las localidades de su entorno más próximas a las zonas de yacimientos, se convierten en un complejo objeto de estudio, encendiendo alarmas diversas y requiriendo una mirada sistémica. Constituyen un eje de estudio específico los procesos asociados a la dinámica socioeconómica y espacial en Neuquén capital, en los que según Landriscini y Preiss (2012) se combinan la dimensión urbana y regional, tales como: i) el sendero evolutivo como polo regional ligado a la producción de energía y las transformaciones más relevantes de los complejos productivos de la Norpatagonia integrados en redes nacionales y globales; 
ii) la tercerización de la base económica, que combina los servicios avanzados centrados en las nuevas tecnologías, y los servicios generales prestados a la población y a las actividades económicas, ligados directamente a la urbanización y la distribución;

iii) la trayectoria urbana como capital provincial y regional, centrada en las actividades e instituciones más relevantes, la infraestructura de servicios de mayor complejidad, y el asiento de múltiples organismos nacionales;

iv) las transformaciones que evidencia el mercado de trabajo urbano y rural, y los cambios en las competencias exigidas, y en la ruralidad, en la que dan cuenta de nuevas actividades y agentes, y

v) la dinámica del mercado de suelo, la ocupación del espacio y los servicios, asociado ello al destino dado a la renta financiera, y a la especulación inmobiliaria.

En línea con lo anterior, pueden señalarse algunas evidencias sobre la ciudad de Neuquén que resultan de la investigación realizada a través de la consulta de fuentes secundarias, particularmente informes técnicos y estadísticas provinciales y locales; y la realización de entrevistas en profundidad a funcionarios públicos provinciales y municipales, y a directivos de empresas, a responsables de cámaras empresarias, referentes de organizaciones no gubernamentales, investigadores y técnicos sectoriales, y representantes de trabajadores:

a. El avance y modernización de las funciones de servicios, que se refleja en nuevos equipamientos y tecnologías, nuevas formas de producción, circulación y gestión, la expansión del terciario urbano, y una creciente articulación funcional y físico-territorial con el entorno regional.

b. Los procesos migratorios, de segmentación laboral y fragmentación socio territorial, y crecientes problemas en la apropiación y uso del suelo urbano, y en la accesibilidad a los servicios básicos, entre otros.

c. Las articulaciones múltiples: por un lado, se refuerzan y multiplican las conexiones espaciales signadas por la contigüidad y el dominio de la ciudad sobre el entorno, y por otro, emergen y se consolidan relaciones de articulación con otras escalas espaciales y agentes externos, producto de la configuración de las cadenas productivas y financieras globales.

d. La dinámica de uso del suelo y la normativa pública, que condicionan el asentamiento humano y de las actividades económicas.

e. La especialización sectorial que refuerza la centralidad urbana.

f. Las nuevas capacidades vinculadas a los activos y las estrategias públicas y privadas de desarrollo en sectores intensivos en conocimiento, que se desenvuelven junto a las capacidades tradicionales, por caso, los avances en la cadena energética de valor, en biotecnología, y TICs. Desde tales perspectivas, se observan fenómenos novedosos en términos del impacto en la ciudad, sus capacidades de adaptación y sus posibilidades de desarrollo. Ellas aparecen limitadas en su alcance, producto de la génesis y los caracteres institucionales, la imperfección de los mercados de nuevas tecnologías y la configuración jerárquica de las tramas productivas. 


\section{El Desarrollo de los Parques Industriales en la Cuenca Neuquina y el impacto de Vaca Muerta}

En un escenario de crisis energética, marcado por el déficit de abastecimiento e inversiones, en mayo de 2012, la Ley 26.741 declaró de Interés Público Nacional el autoabastecimiento de hidrocarburos, y de utilidad pública y sujeto a expropiación el $51 \%$ de las acciones de YPF S.A. y Repsol YPF Gas S.A. A partir de entonces, YPF tuvo un rol protagónico en la nueva estrategia gubernamental de recuperar la producción de hidrocarburos, tanto en petróleo como en gas, y de reducir las importaciones. Estas expectativas se vieron reforzadas por la planificación definida por la renovada conducción de YPF, cuyos ejes centrales establecieron el avance sobre yacimientos maduros, el desarrollo de clusters de empresas vinculados a los reservorios no convencionales y el aumento en la refinación a fin de elevar el uso de la capacidad instalada.

La decisión de impulsar el desarrollo de Vaca Muerta se sustentó en visiones optimistas privadas y gubernamentales centradas en los siguientes factores: i) el potencial de recursos no convencionales; ii) la búsqueda del autoabastecimiento; iii) el crecimiento de las reservas probadas de hidrocarburos de reservorios no convencionales, especialmente de gas; iv) la infraestructura de gasoductos y oleoductos existente; v) el marco legal y de incentivos para las inversiones.

Estos factores configuraron un nuevo escenario, que de concretarse permitiría revertir la declinante perfomance de la actividad convencional en la Cuenca Neuquina. Dadas las características de la explotación no convencional, altamente demandante de servicios y provisión de insumos, se ha configurado una nueva división del trabajo en la Cuenca, y una creciente demanda de las operadoras hacia empresas de la cadena de proveedores, en relaciones diversas de contratación y subcontratación y distintos grados de acoplamiento. Altamente impactadas por esta situación resultan las ciudades de Neuquén, y las de Centenario y Añelo, situadas en el eje circulatorio entre la principal ciudad de la provincia -Neuquén- y la zona productiva que concentra el mayor porcentaje de operaciones. Esto ha generado una creciente demanda de suelo urbano para la radicación de empresas, que los gobiernos locales intentan regular mediante el fortalecimiento de sus parques industriales. Asimismo crece de modo exponencial el flujo de equipos de transporte de cargas y personal que se desplazan a diario entre ciudades extraregionales, áreas de residencia y zonas de exploración y producción en la Cuenca. (Ver Mapa sobre área productiva) En tanto, las políticas provinciales enfrentan el desafío de conjugar la planificación urbana con el crecimiento de la base económica y el desarrollo de una plataforma industrial y de servicios que contribuya al crecimiento de la actividad y a la formación de recursos humanos en los nuevos sistemas técnicos. 
Áreas de exploración y producción hidrocarburífera en el sector neuquino de la Cuenca

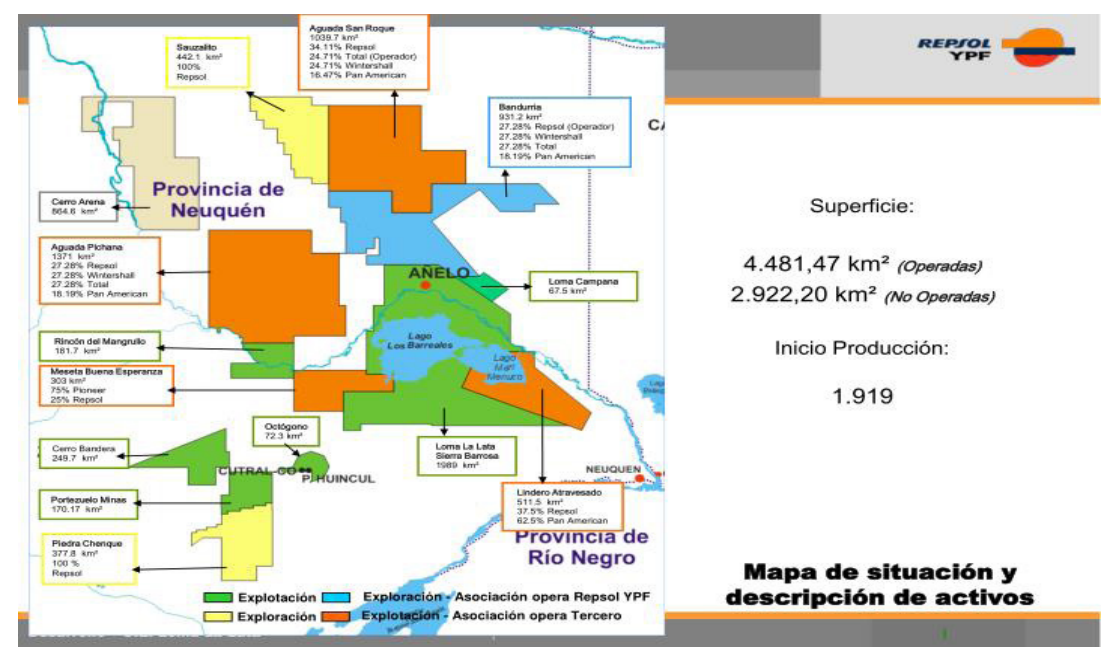

Área productiva de la formación Vaca Muerta. Ciudades y demanda de ampliación de ejidos

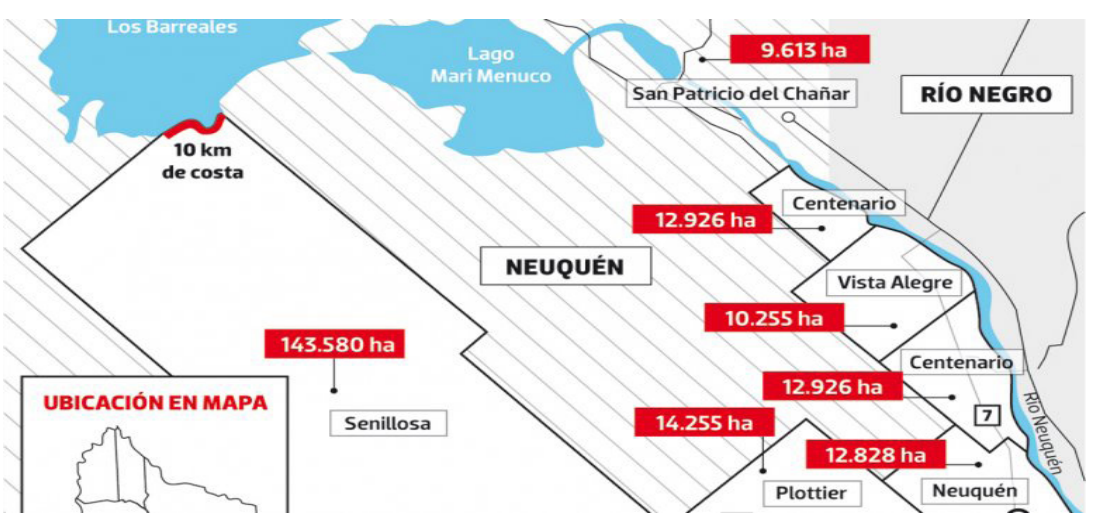

Fuente: Consejo Provincial de Planeamiento y Desarrollo. Provincia de Neuquén.

La provincia del Neuquén cuenta con 18 parques y áreas industriales, seis de ellos son de administración provincial: Neuquén, Zapala, Polo Químico y Petroquímico de Plaza Huincul- Cutral Có, Rincón de los Sauces, Picún Leufú y Buta Ranquil. En este último caso, la jurisdicción provincial y municipal, comparten la definición de un área industrial. En el resto, la administración de los parques es municipal: Añelo, Centenario, Senillosa, Plottier, Cutral Co y Plaza Huincul, Vista Alegre, San Patricio del Chañar, Villa El Chocón, Rincón de los Sauces, Junín de los Andes y Chos Malal. Por su parte, en Zapala se ha creado una Zona Franca privado-pública con el objeto de promover actividades de logística e intercambios transfronterizos con énfasis en la producción regional; y en la ciudad de Cutral Có; , a 100 km de la capital se encuentra localizado un Parque Tecnológico Provincial, en el que se impulsan actividades de producción y ejecución de proyectos de investigación aplicada, de construcción de equipos y sistemas, de transmisión y generación de tecnologías y ciencias, y de asistencia técnica volcada a operaciones y desarrollos tecnológicos. (Ver Mapa de Parques Industriales) 
Del avance de conocimiento producto de la investigación realizada, se concluye un alto impacto directo territorial de la explotación de recursos no convencionales evidenciado en los cambios en curso en la configuración de las ciudades de Neuquén, Centenario y Añelo, generados a partir de la multiplicación de la radicación de bases de empresas en las ciudades y de campamentos en las áreas de producción junto al trabajo de los equipos en el upstream fundamentalmente.

Localización de los Parques industriales en la provincia de Neuquén

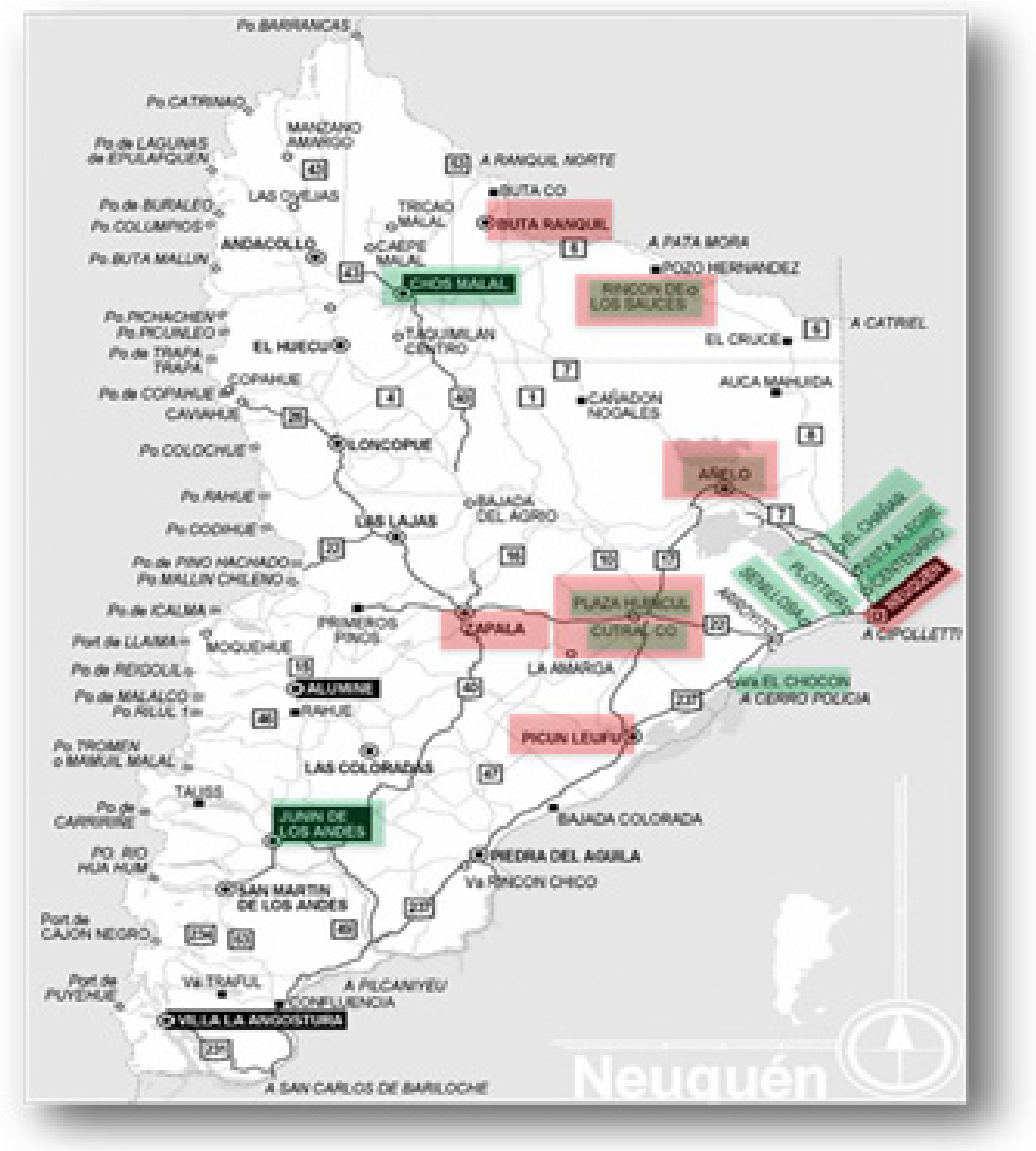

Fuente: Consejo Provincial de Planeamiento y Desarrollo. Provincia de Neuquén.

Esto ha llevado a las administraciones locales y provincial a poner en marcha expansiones de las superficies a adjudicar, y a intervenir mediante la modificación de la normativa que regula el diseño y funcionamiento de las áreas industriales y de servicios, intentando morigerar los efectos sobre el ordenamiento urbano. En tanto las administraciones locales presentan grados disímiles de capacidad política, técnica y administrativa para enfrentar esta situación, al mismo tiempo que deben articular este proceso con el fortalecimiento de la economía local y la generación de empleo, el Estado provincial proyecta y formula políticas de estímulo a la generación de empresas especializadas, tanto en la provisión de servicios como en la producción de insumos. Esto podría redundar en el up-grade tecnológico del conjunto de empresas del sector y en la incorporación de nuevas actividades industriales en territorio neuquino, 
dependiendo de las políticas nacionales en cuanto a precios internos del gas y el petróleo en boca de pozo, regalías, tarifas, y las relativas a la importación de bienes de capital e insumos.

Más allá de ello, las políticas de parques industriales pueden contribuir a fortalecer las actividades existentes y a atraer nuevas inversiones. La existencia de un cluster de empresas asociadas a la explotación hidrocarburífera, operará positivamente en la trayectoria de las ciudades o la región en la medida que las empresas puedan usufructuar las economías de localización que explican las ventajas derivadas de la concentración espacial: los beneficios derivados de la posibilidad de compartir los costos de ciertos recursos colectivos; la reducción de costos de transacción por la localización en un mismo espacio; y el fortalecimiento de la comunicación, y la desintegración vertical intra-firma de ciertas operaciones a favor de una integración al interior del cluster; la creación de un mercado de trabajo especializado; y la circulación de conocimiento y aprendizaje localizado. De verificarse que las firmas instaladas pueden usufructuar estas ventajas, el cluster podría constituirse tanto en el centro de las políticas públicas como en un polo de atracción para la instalación de nuevas empresas y la ampliación de otras, y en un espacio de aprendizaje tecnológico, pudiendo conducir al reforzamiento de una nueva trayectoria en la base económica urbana de las ciudades donde se localizan los parques industriales. Esta posibilidad dependerá de la trayectoria pasada de la economía local, de las alternativas que plantea el devenir económico regional/local y de las capacidades de las ciudades para aprovechar el nuevo escenario, en especial la generación de economías de localización, el alcance de economías de urbanización y de los proyectos institucionales que impulsen el sector público provincial, y los gobiernos locales.

\section{Resultados, conclusiones e hipótesis de investigación sobre las trayectorias económicas de las ciudades bajo análisis}

Puede señalarse al respecto:

- Neuquén capital a través de la ampliación de su parque industrial actual, ha definido un proyecto que potencia la radicación de las grandes empresas del sector petrolero, en una interacción provincial-municipal que deriva en el posicionamiento del parque industrial local (PIN) como el principal centro logístico y de servicios de la actividad en la zona productiva de la formación Vaca Muerta, reforzando las economías de localización. En ello las economías de urbanización juegan un rol preponderante, dado el rol de Neuquén como centro económico, administrativo, comercial y residencial de la región, y la consolidación del PIN como referente a nivel provincial, con creciente especialización en el sector hidrocarburos y un área especial para la operación de grandes plantas.

- Centenario recibe la demanda de suelo para uso industrial 
y de servicios de las pequeñas y medianas firmas regionales que ha desbordado a la capital. La ciudad, a pesar de evidenciar una fuerte tradición agroindustrial, cuenta con la posibilidad de generar la radicación de un bloque de empresas que por su impacto directo e indirecto pueden inducir cambios significativos en el perfil económico de la ciudad, a partir de la radicación de inversiones públicas y privadas de diversificación relacionadas a los hidrocarburos. Esto permitiría generar economías de localización en la medida que se verifique una interacción entre empresas de servicios especiales, proveedoras pequeñas y medianas y compañías operadoras, lo cual requiere del desarrollo de una institucionalidad empresaria local, del reforzamiento de las capacidades organizativas y de una fuerte interacción con el sector público y el entorno científico tecnológico. En cuanto a las economías de urbanización, los cambios esperados en la estructura económica combinados con el auge de la inversión residencial y el crecimiento poblacional plantean interrogantes sobre las ventajas de urbanización que puedan generarse, teniendo en cuenta su cercanía con la ciudad capital. (8km)

- Añelo evidencia una transformación que representa un proceso abierto debido a que el desarrollo actual y planificado de su parque industrial se da en el contexto de una historia local vinculada a un incipiente desarrollo agropecuario en profunda transformación por el impacto de la explotación de los hidrocarburos no convencionales. Se ha creado un parque industrial municipal, y un parque provincial con participación privada en la dotación de los servicios. Si bien está previsto un fuerte impacto producto de la radicación de empresas, su rol de base de servicios a yacimientos, no permite pensar en la generación automática de economías de localización que puedan inducir una dinámica que supere la actividad tradicional de las empresas, y plantea el desafío de superar la dinámica local asociada a los "pueblos petroleros". Hoy sufre el efecto de la caída del precio internacional del crudo, y de la reducción de las inversiones en exploración de YPF.

\section{Las pequeñas y medianas proveedoras de los hidrocarburos en la Cuenca}

Las firmas pequeñas y medianas encuestadas en la investigación fueron un total de 25, entre las que se integraron al Programa Sustenta de Desarrollo de Proveedores de YPF y las que operan por fuera del mismo, siendo 500 unidades en total las del segmento PyME en la Cuenca Neuquina que integran el segundo eslabón de la cadena de valor de los hidrocarburos (Ver figura de la Cadena de valor). 
Cadena de valor de los hidrocarburos, firmas con actividad en la Cuenca Neuquina

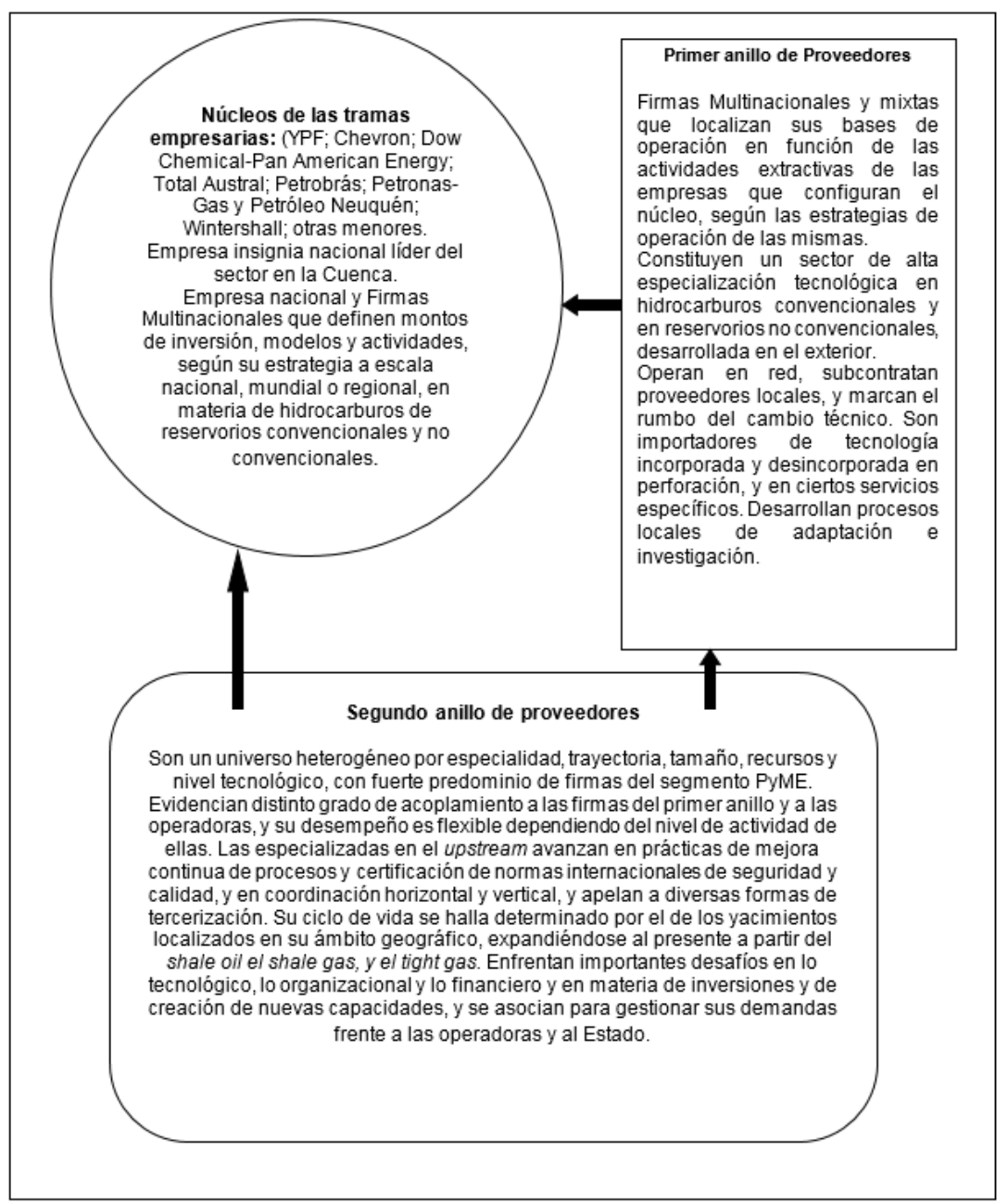

Fuente: Elaboración propia sobre la base de Kozulj y Lugones, 2007.

Del análisis efectuado sobre los diagnósticos, propuestas de mejora e intervenciones hechas por el Instituto Nacional de Tecnología Industrial sobre 16 firmas pequeñas y medianas durante 2014/2015, como parte del Programa Sustenta de Desarrollo de Proveedores de YPF, destacan las siguientes cuestiones:

1- el predominio del empresario intuitivo en este segmento de firmas, que logra hacer crecer la fábrica sin otro conocimiento que la propia herramienta y su oficio;

2- un número reducido de nuevos empresarios o empresarios de segunda generación profesionalizados que encuadran en el tipo Empresario técnico en gestión que se caracteriza por haberse capacitado en la teoría del Management.

3-la conformación de unidades de gestión pequeñas que a partir de recursos humanos profesionalizados coordinan el desenvolvimiento y los proyectos de la

pequeña y mediana empresa, y que incorporan la figura equivalente a la del Empresario Tecnólogo, el que considera predominantemente la variable tecnología informática y electrónica, 
Impactos de la explotación de reservorios no convencionales de hidrocarburos sobre la actividad industrial y de servicios en el sistema de ciudades. El caso de la Cuenca Neuquina en la Patagonia Argentina

y la gestión de redes entre el núcleo empresario y las unidades que operan a campo, y con proveedores, subcontratistas, y clientes.

4- un número reducido de nuevas pequeñas y medianas empresas en las que aparece el tipo Empresario Emprendedor, que tiene la variable manejo del negocio a partir de su intuición más la variable del management o técnicas de gestión.

5- un número más reducido aún de firmas pequeñas y en particular medianas en las que se identifica el Empresario Tecnoemprendedor o el núcleo de conducción familiar y no familiar que tiene las variables de negocio, más la de management más la de tecnología informática-electrónica.

Agregado a lo anterior, cabe destacar que las especificidades de las pequeñas y medianas proveedoras de bienes y servicios a los hidrocarburos, y de quienes las gestionan, han evidenciado -según los diagnósticosla necesidad de desarrollar renovados esfuerzos en la formulación de políticas que promuevan las potencialidades de este actor; ello ha llevado a reinterpretaciones de las políticas tradicionales en la cuestión -más orientadas a los casos individuales-, hacia una visión más comprensiva de las condiciones y necesidades en que operan estas firmas, y los desafíos que les representa intentar comportamientos innovadores para competir. Dentro de ello está cobrando creciente importancia la necesidad de proponer políticas que potencien la capacidad de gestión por parte de este tipo de empresas desde un enfoque sistémico, en el que se reconozcan los condicionantes del contexto para esa gestión, como son la trayectoria de los agentes locales, las capacidades técnico-económicas acumuladas, la disponibilidad de recursos, las economías de aglomeración, el ambiente y los vínculos con instituciones, la configuración y el funcionamiento del mercado de trabajo, y la dotación de infraestructura, entre otros. Estos temas convocan a seguir la investigación.

Además, en el caso de las firmas de este segmento en la Cuenca Neuquina, el proceso de innovación no se asocia a la formalización y las oficinas de Investigación y Desarrollo, ya que el conocimiento tácito, los esfuerzos informales y las mejoras incrementales adquieren en ellas mayor relevancia en los procesos de aprendizaje, en comparación con las grandes empresas. Para impulsar la innovación que el sector demanda, es necesario entonces que ellas mejoren la capacidad de vinculación con las grandes empresas, que participen de redes productivas y tecnológicas con centros especializados, institutos y universidades, que apunten a fortalecer sus planteles de trabajadores cualificados, y que establezcan vínculos con el entorno social y productivo local, en vez de intentar desarrollos introvertidos.

A ello se agrega la situación de fuerte heterogeneidad y rezago en las firmas de este segmento en términos de sendero evolutivo y desempeño, también reconocida para el continente y el país en numerosos estudios. Las pequeñas y medianas empresas más dinámicas e innovadoras son relativamente pocas a nivel local; son por lo general unidades profesionalizadas, con presencia de ingenieros como titulares o gerentes, con trayectoria en actividades industriales o de servicios especializados, y son las que se benefician de las políticas destinadas a impulsar la innovación en el segmento. Las firmas menos dinámicas y no profesionalizadas, que son la mayoría, requieren de propuestas diseñadas ad hoc a partir de sus problemas, para lograr incrementos importantes de productividad; en 
ello, la vinculación con las universidades y centros tecnológicos resulta imprescindible y de gran utilidad. Cabría facilitarles la introducción de nuevas tecnologías, con lo que podrían concretar un mayor intercambio de información, promover formas de colaboración con instituciones y otras firmas, participar en redes, el acceso al financiamiento, etc. Ello les permitiría modificar gradualmente el modo de operación técnica y la gestión general, incluyendo la implementación de cambios incrementales. En ese marco, las universidades, que como parte del sistema regional de innovación deben asociarse a las firmas para reforzar la concreción de opciones productivas sustentables, enfrentan múltiples debilidades, de recursos, visiones, rutinas y organización, siendo conveniente revisar sus estructuras y procesos y crear centros y proyectos de vinculación tecnológica universidad-empresa ad hoc.

A nivel territorial, un aspecto relevante para potenciar el desarrollo de las pequeñas y medianas proveedoras industriales y de servicios específicos en cadenas globales derivadas de los recursos naturales, es su participación en agrupamientos productivos; pueden asociarse a los parques y aglomerados industriales según sus perfiles específicos, en tanto éstos incorporen infraestructura científica y en espacial tecnológica, laboratorios, centros de servicios y certificación, conectividad, etc. La literatura sobre el tema y la experiencia internacional (Lastres, 2003), señalan que la participación en estos agrupamientos genera notables ventajas para el desarrollo de este segmento de firmas, en tanto existen economías de proximidad, tecnológicas y organizacionales. Ello es particularmente importante, tanto por lo que permite en cuanto al acceso a información relevante sobre tecnología, oportunidades de negocios y alianzas posibles, como respecto a la identidad, construcción de un capital territorial, y variadas economías externas, feed backs en desarrollos e investigaciones, fortalecimiento institucional, ganancia de escala y conocimiento, articulación insumo-producto, desarrollos conjuntos de procesos e infraestructura, desarrollo de productos o mercados, legislación a nivel territorial, y capacidad de negociación en la cadena. Asimismo, el impacto y las posibilidades de upgrading se ven potenciadas si en esos agrupamientos productivos concurren las universidades, o centros de investigación con presupuestos y recursos humanos e institucionales ad hoc, ya que ello amplifica el impacto que este vínculo supone.

En ese contexto, tal como señalan Yoguel, et al 2007, la política tecnológica debe proponerse: i) mejorar las condiciones micro de generación de competencias y procesos de aprendizaje de firmas individuales, redes productivas y sistemas locales, ii) crear externalidades y amplificarlas mediante la transformación del espacio en el que actúan los agentes, iii) actuar sobre rutinas y modalidades de funcionamiento de las firmas e instituciones, y iv) actuar sobre los articuladores de redes y sistemas locales existentes.

Para ello debe tener como ejes: i) el fortalecimiento del sistema local y nacional de innovación, ii) el desarrollo de redes de firmas e instituciones, iii) las mejoras de la articulación entre las universidades y centros tecnológicos con las empresas, iv) la cooperación y complementación, v) un carácter sistémico y vi) el desarrollo de un proceso de lectura de necesidades.

Además, pareciera deducirse de las investigaciones de Kozulj y Lugones (2007) y de Landriscini et al. (2015) que el hecho de ubicarse en un 
"anillo de proveedores" más cercano al núcleo operativo y empresas de servicios especiales puede ser favorable a las condiciones contractuales de la relación de las proveedoras pequeñas y medianas con sus clientes, y al intercambio de información tecnológica. En este sentido, un subgrupo de la muestra seleccionada del Programa Sustenta, y de las restantes firmas conectadas y consultadas, han logrado consolidar su posición en el primer anillo de proveedores, y han prestado servicios de elevada complejidad con una flexibilidad superior a sus competidores más grandes, por su carácter de pequeñas y medianas empresas, lo que en algunos de los casos se vincula a su reputación como empleados cualificados, técnicos o ingenieros de las firmas clientes en períodos previos. Es así que los mandos medios en las firmas que los poseen, desarrollan un papel esencial, teniendo en cuenta que: 1 . su presencia permite intercambios de conocimiento a un cierto nivel de agregación y entre sectores de la firma que no se dan en el caso de empresas en las que hay un dueño-gerente que se relaciona directamente con los operarios; y 2. ellos son quienes aglutinan el conocimiento que el resto del personal operativo adquiere en la prestación de las tareas, y combinando ese know-who (modo de distribución del conocimiento) interno de la organización con el know-why (bases científicas del proceso) en sus reflexiones junto con el dueño-gerente o equipo emprendedor, han posibilitado innovaciones de producto o de proceso. El know-why en los casos de firmas que cuentan con personal profesional en su dotación, no sólo ha posibilitado concretar innovaciones de producto o de proceso, sino que le permite a la organización reconocer el conocimiento que se produce internamente para registrarlo y socializarlo al resto de los empleados y poder reutilizar el propio conocimiento. Su acumulación crea y recrea un sendero de innovación para la firma. Las organizaciones que no hacen eso, dependen de la información que obtienen del entorno, recurso que es poco explotado en el conjunto de firmas analizado, y que suele evidenciar barreras de acceso económicas o técnicas.

En estas firmas en que el conocimiento y la facultad decisional está concentrada en el dueño-gerente, la organización cuenta con límites al crecimientos dados por la capacidad de gestión que esa persona tenga, a lo que se agregan los riesgos de inestabilidad que la personalización trae consigo hacia el futuro. Las firmas que cuentan con cierto know-how de negocios, valoran en mayor medida el input que puedan brindar los trabajadores. Adicionalmente, uno de los perjuicios del empobrecimiento del trabajo, lo constituye la migración de los trabajadores hacia las empresas multinacionales del sector. Si bien la autonomía que se brinde a los trabajadores debe ir acompañada del conocimiento que se corresponde con cada nivel, el análisis de casos evidencia que los beneficios de la transferencia de conocimiento pueden materializarse en la medida en que la empresa se enfoca en la formación de competencias particulares en sus empleados, de acuerdo a las necesarias para cada puesto, combinando ese enfoque con la rotación entre tareas de diferente dificultad y una evaluación de desempeño periódica. Esto coincide con algunas características de las organizaciones formativas que mencionan Erbes et al. (2014). La vinculación con el entorno empresarial-institucional y científico de los casos estudiados muestra una modalidad de aprendizaje restringida, en la que el crecimiento de las firmas y su aprendizaje colectivo, se ve afectado por el escaso aprovechamiento 
de las relaciones con el entorno para apropiarse de nuevos conocimientos. Ello aparece como de responsabilidad compartida entre las firmas y los organismos universitarios y de ciencia y tecnología, con rutinas que frecuentemente muestran desarrollos introvertidos.

Con respecto a la relación con otras empresas, los casos abordados registran algunos avances en base a su relación transaccional con sus clientes. Cuando los clientes realizan algún requerimiento especial, esto exige esfuerzos de data mining para conocer si la empresa puede brindar ese servicio u ofrecer ese producto y en qué condiciones lo puede hacer. La ausencia de proyectos colaborativos con otras empresas a nivel horizontal o vertical es el denominador común en las experiencias estudiadas. En los casos estudiados que evidencian una menor distribución de la toma de decisiones al interior de la firma, esta centralización coincide con una concentración de la facultad de relacionamiento con otros actores del sistema productivo y de innovación, y por lo tanto de obtención de conocimiento desde el entorno en el dueño-gerente o el equipo emprendedor. Estos emprendimientos surgen con base en la experiencia de los emprendedores en empresas multinacionales, y ellos utilizan esa base de conocimientos para seguir aprendiendo del entorno. En la misma línea, las relaciones con las instituciones de conocimiento del sector se restringen al canal tradicional, específicamente a la contratación de personal egresado de escuelas técnicas o universidades, y a la demanda de servicios en oportunidades puntuales. En este sentido la potencialidad del desarrollo de un canal bidireccional de relaciones a largo plazo con instituciones de conocimiento tales como la Facultad de Ingeniería de la Universidad Nacional del Comahue localizada en Neuquén capital, la Universidad Tecnológica Nacional asentada en Plaza Huincul, el Instituto de Investigaciones Aplicadas (INVAP S.E) con sus instalaciones en San Carlos de Bariloche, el Instituto Nacional de Tecnología Industrial (INTI) con sede en Neuquén, y con YPF Tecnología (YTEC) -entre otrasestá lejos de materializarse satisfactoriamente.

\section{Resultados y nuevo conocimiento producido a partir de la indagación acerca de las pequeñas y medianas proveedoras de la cadena de los hidrocarburos en la Cuenca Neuquina}

En función de lo indagado, de la sistematización del conocimiento producido sobre las pequeñas y medianas empresas de la cadena de los hidrocarburos en la Cuenca Neuquina, resultan los siguientes indicios y conclusiones que abren nuevas hipótesis de investigación:

a) El origen de la empresa, y el titular y su trayectoria. En las firmas relevadas, son factores que condicionan en gran medida la evolución posterior de la delegación del proceso decisional y del conocimiento necesario para la toma de decisiones. Incluso se observan situaciones en las que se desaprovecha el conocimiento de los operarios, en tanto se les otorga una menor posibilidad de intervención en el proceso decisional de la que podrían asumir en función del conocimiento que poseen sobre el proceso productivo y sobre los clientes.

b) Gestión del conocimiento. El know-how (cómo producir bienes 
o prestar servicios) relativo al proceso, se distribuye en general entre todo el personal, mientras que el know-who (con quiénes) y el know-what (qué producir o qué servicios prestar) son decisiones concentradas por los mandos medios o los socios gerentes que son quienes tratan con los clientes y con los proveedores. En el know-what, predomina la información tácita por sobre la codificada. El know-why (bases científicas de los procesos encarados) en general está concentrado en el personal profesional o técnico altamente calificado, y predominan esfuerzos informales de transferencia de conocimiento en los procesos de inducción de nuevo personal. Hay firmas que evidencian intercambios orientados a las competencias que se pretende desarrollar para el puesto, y algunas de ellas incorporan la evaluación de desempeño y la rotación entre tareas de diferente nivel de dificultad.

c) Registro y uso de información para la toma de decisiones. Es escaso el registro sistemático de información y la planificación a largo plazo, y no abundan los mecanismos complejos para la toma de decisiones. Esto parcialmente puede explicarse por la volatilidad de la industria y la dependencia del nivel de actividad de las firmas con respecto al núcleo de operadores y a los subsiguientes anillos de proveedores en la cadena. Es probable que los factores que influyen en la baja utilización de información para apoyar las decisiones, tengan que ver con las capacidades de la empresa y del equipo emprendedor, cuyos conocimientos están en general más ligados a lo productivo y lo relacional que a la gestión. En otros casos, se verifica un acceso diferencial a las fuentes de información consultadas para la toma de decisiones, que va en línea con el grado de delegación de dicho proceso en los empleados.

d) Respecto al aprovechamiento de externalidades y los vínculos con el entorno científico tecnológico, se observa en las firmas relevadas que todas intentan incorporar egresados de colegios secundarios técnicos, lo cual en algunos casos suplen con experiencia en el rubro. Otras incorporan profesionales para integrarlos a sus mandos medios e involucrarlos en la prestación del servicio. Al analizar las capacidades que las firmas estudiadas disponen para innovar, la vinculación más importante que tienen con su entorno es la relación con proveedores y clientes a partir de mutuas demandas, y -en muchos casos- son los requerimientos que plantea el cliente los que impulsan a las firmas a desarrollar comportamientos centrados en la mejora continua.

\section{A modo de reflexión final}

De la investigación resulta que la implementación de los parques y áreas industriales con infraestructura y servicios de uso común, además de concertarse entre las distintas jurisdicciones del Estado y con los distintos segmento de empresas dentro de la cadena de valor, debe complementarse con acciones que promuevan la renovación tecnológica y de gestión de las proveedoras pequeñas y medianas empresas; que incentiven cambios en la organización del trabajo y la toma de decisiones hacia modos más profesionalizados, horizontales y participativos, así como nuevas dinámicas de elaboración y registro de información y vinculación con el entorno científico e institucional. Resulta necesario 
aumentar la densidad de los vínculos creativos en la adopción de las nuevas tecnologías, y el desarrollo local de alternativas innovadoras en exploración, producción y logística, que otorguen prioridad a la preservación del medio ambiente. Al respecto el sistema de innovación debe asumir la reducción del riesgo en la cuestión del fracking.

Adicionalmente, no sólo corresponde a las universidades regionales ubicadas en Neuquén capital y en Cutral Có y Plaza Huincul investigar los procesos de cambio asociados a la nueva fase de desarrollo de los hidrocarburos, revisar la complejidad de las situaciones que emergen, los desfasajes temporales, los problemas ambientales y los de ordenamiento territorial; y evaluar impactos. Los gobiernos provinciales y locales deben convocar a los equipos responsables de las actividades científicas y tecnológicas a intervenir como agentes de cambio junto a los actores locales, las redes de pequeñas y medianas empresas y los ejecutores de programas y proyectos que resultan de las nuevas modalidades de exploración, explotación y transformación de los recursos naturales, aportando conocimiento y gestión para encaminar desarrollos institucionales y productivos sustentables económica, social y ambientalmente.

\section{Referencias}

Anlló, G. et al. Innovación y competitividad en tramas globales. Colección Documento de Proyecto. Santiago de Chile. CEPAL. Naciones Unidas, 2009.

Barletta, F. et al. Introducción. En Tópicos de la teoría evolucionista neoschumpeteriana de la innovación y el cambio tecnológico UNGS: Buenos Aires: Miño y Dávila, pp. 11-32, 2014.

Becattini, G. "Del distrito industrial marshalliano a la 'teoría del distrito'. Una breve reconstrucción crítica . El distrito industrial marshalliano". Investigaciones Regionales, p. 9-32, 2002.

Boschma, R. "Path creation, path dependence and regional development" in J. Simmie and J. Carpenter (eds.), Path Dependence and the Evolution of City Regional Economies, Working Paper Serie, No. 197, Oxford: Oxford Brookes University, p. 40-55, 2007.

Briano, L., et al. El lugar de la industria. Los parques industriales en la reestructuración productiva y territorial de la Región Metropolitana de Buenos Aires". Revista Eure Santiago de Chile, Vol. XXIX, № 86, p.26-45. mayo 2003.

Camagni, R. Economía Urbana. Antoni Bosch. Barcelona, 2005.

Campolina Diniz, C. y Crocco, M. (org.) Economía Regional e Urbana. Contribucioes Teóricas Recentes. Belo Horizonte: Editora UFMG. 2006.

CEPAL. Impacto socioeconómico de YPF desde su renacionalización Desempeño productivo e implicancias sobre los mercados laborales y el 
Impactos de la explotación de reservorios no convencionales de hidrocarburos sobre la actividad industrial y de servicios en el sistema de ciudades. El caso de la Cuenca Neuquina en la Patagonia Argentina

entramado de proveedores Vol. I. Santiago de Chile y Buenos Aires, 2015.

Damaskopoulos, T. et al. "Extended and Dynamic Clustering of SMEs". Engineering Economics, 56(1), Kauno Technologijos Universitetas, p. 1121, 2008.

David, P. A. Path dependence. A foundational concept for historical social science. Cliométrica. The Journal of Historical Economics and Econometric History, v.1, no.2, 2007.

Delfini, M. et al. (Comp.) Innovación y empleo en tramas productivas de Argentina. Univ.Nacional de General Sarmiento. Buenos Aires. Ed. Prometeo, 2007.

Di Sbroiavacca, N. Shale Oil y Shale Gas en Argentina . Estado de situación y prospectiva. IIEE. Fundación Bariloche, 2013.

Dini, M., y Stumpo, G. Políticas para la innovación en las pequeñas y medianas empresas en América Latina. Santiago de Chile.CEPAL, 2011.

Easterby-Smith, M., et al. Dynamic capabilities and knowledge management: An integrative role for learning? British Journal of Management, 19(3), p.235-249, 2007.

Erbes, A. et al. El rol de la organización del trabajo en el desarrollo de procesos de aprendizaje. En Tópicos de la teoría evolucionista neoschumpeteriana de la innovación y el cambio tecnológico UNGS. Buenos Aires: Miño y Dávila, pp. 287-318, 2014.

Estrada, S., y Dutrénit, G. "Gestión del conocimiento en PyMEs y desempeño competitivo". Engevista, 9 129-148 dez. 2007.

Ferraro, C. (comp.) Clusters y políticas de articulación productiva en América Latina. Santiago de Chile, CEPAL FUNDES, 2010.

Ferraro, C., y Stumpo, G. Políticas de apoyo a las PyMEs en América Latina: Santiago de Chile: CEPAL, 2010.

Garay, A. (coord.). "Informe 1. Parques, áreas y zonas industriales: de los conceptosalaacción"; Informez: "Parquesindustriales:aciertosy desaciertos". Asistencia técnica al parque industrial de La Plata. La Plata: PNUD. 1996.

Gatto, F. "Cambio tecnológico neofordista y reorganización productiva. Primeras reflexiones sobre sus implicaciones territoriales". F. Alburquerque, et al. Revolución tecnológica y reestructuración productiva: impactos y desafíos territoriales. Buenos Aires: ILPES/ONU - IEU/PUC - GEL. 1990.

Gorenstein, S. et al. (Comps.) Economía urbana y ciudades intermedias. Trayectorias pampeanas y norpatagónicas. Buenos Aires. Ed. Ciccus, 2012. 
Helmsing, A. Teorías de desarrollo industrial regional y políticas de segunda y tercera generación". Revista Eure, Santiago de Chile, Vol. XXV. № 75 pp 5-39, set.1999.

Henríquez Amestoy, L. Política para MIPYMEs frente a la crisis. Conclusiones de un Estudio Comparativo de Europa y América Latina. Documento de trabajo. EuropeAid. Organización Internacional del Trabajo. 2009.

Hildreth, P. Roles and Economic Potential of English Medium Sized Cities: a Discussion Paper. London: IIED. England, 2006.

Hodgson G. M. (Ed.) Introduction in: A Modern Reader in Institutional and Evolutionary Economics. Key concepts. Cheltenham UK. E. Elgar, p. 13-29, 2002.

Kantis, H., et al Políticas de Fomento al Emprendimiento Dinámico en América Latina: Tendencias y Desafíos. Caracas, Corporación Andina de Fomento, 2012 (09).

Katz, J., y Zamorano, F. Capacidad innovadora de las pymes y las políticas públicas: el caso chileno. En Dini , M. y Stumpo, G. Políticas para la innovación en las pequeñas y medianas empresas en América Latina. CEPAL. Santiago de Chile, p. 89-124, 2011.

Kline, S. y Rosenberg, N. "An over view of innovation". En The positive Sum Strategy: Harnessing Technology for Economic Growth. Ed. Landau y Rosenberg. Washington DC. National Academy Press. p. 275-305, 1986.

Kozulj, R. Los principales desafíos del sector energético argentino: un panorama complejo Neuquén, FAEA - Fundación Bariloche, p. 1-43, 2011.

Kozulj, R., y Lugones, M. Estudio de la trama de la industria de los hidrocarburos en la Provincia de Neuquén. En Delfini, M. et. al. (comp.) Innovación y empleo en tramas productivas de Argentina. Universidad Nacional de General Sarmiento. Buenos Aires. Ed.Prometeo, p. 35-65, 2007.

Lagerholm, M. \& Malmberg, A. Path dependence in economic geography, in L. Magnusson y J. Ottosson: The evolution of path dependence. Uk. Edit. E. Elgar, 2009.

Lall, S. Technological capabilities and industrialization. World Development, New York, p.165-186, 1992, 20(2).

Landriscini, S. G. y Orlandini, M. Innovación y coordinación en PyMEs de servicios petroleros en el cluster shale de Vaca Muerta". En Ascúa, R. et al. - Lecturas seleccionadas de la XIX Reunión Anual de la Red PYME Mercosur. Campinas: Inst. de Economía de la Universidad Estadual de Campinas. p. 230-299, 2014. 
Landriscini, S. G., y Orlandini, M. El desarrollo regional en la Cuenca Neuquina. Hidrocarburos de reservorios no convencionales y múltiples desafíos. Revista Pilquén - Sección Ciencias Sociales, CURZA. UNCo Viedma No 18 (1), p. 50-62, junio 2015.

Landriscini, S.G. et al. El escenario Shale y los desafíos en la Cuenca Neuquina. Aprendizaje tecnológico y creación de capacidades en PyMes" En R. Ascua et al; Lecturas seleccionadas de la XX Reunión Anual de la Red PyME Mercosur. Vol. I. Bahía Blanca: UNS.UPSO. IIES:CONICET. Red PyME Mercosur, p. 72-114, 2015.

Landriscini, S. G. et al. El desarrollo de los hidrocarburos de reservorios no convencionales en la Cuenca Neuquina: cambios en las ciudades, en su funcionalidad y vínculos; el rol de los parqrues industriales". XI Bienal del Coloquio de Transformacines Territoriales. Salto. Uruguay. Universidad de la República. 26 al 29 de julio de 2016. Web BIENAL.

Landriscini, S. G. y Robles, L. Informe Final Proyecto de Vinculación Tecnológica sobre Pequeñas y Medianas Empresas de los HIdrocarburos en la Cuenca Neuquina. Acuerdo de trabajo UNCOMAHUE, YPF Programa Sustenta Regional Neuquén e Instituto Nacional de Tecnología Industrial sede Neuquén. 2016.

Landriscini, S. G. y Robles, L. "Información, decisiones y participación en Pymes de hidrocarburos de la Cuenca Neuquina. El rol del dueño y del sistema regional de innovación". En Ascúa, R. et al; Lecturas seleccionadas de la XXI Reunión de la Red PYME Mercosur Vol. 1 Tandil. UNICEN. 2016. p. 56-81.

Lastres, H. "Systems of Innovation and Development". Seminario Globelics de Río de Janeiro. Global Network for Economics of Learning, Innovation adn Compegtence building Systems. Anais... Río de Janeiro, 2003. 2 a 5 de noviembre.

Lundvall, B.-Å. Product innovation and user-producer interaction. Research Series Aalborg. №31. Aalborg University Press. 1985.

- National Innovation Systems - Analytical Concept and Development Tool. Copenhagen, 2005.

Maillat, D. et al "Innovation Networks and Territorial Dinamycs: A Tentative Tipology. In B. Johansson, et al. (Editors) Patterns on a Network Economy. Springer-Verlag Berlin, p.33-5, 21994.

Martin, R. and Sunley, P. "Path Dependence and Regional Economic Evolution”. In Papers in Evolutionary Economic Geography. Utrecht University. p. 395-438, 2006.

Martin, R. et al. Path dependence and local innovation systems in city 
regions". In: Innovation management policy and practice. Volume 10, Issue 2-3, 2008, oct.-dec.

Méndez R. El territorio de las nuevas economías metropolitanas. Revista Eure, Santiago de Chile. Vol. XXXIII, № 100, p. 51-67, dic. 2007.

Nelson, R. \& Winter, S. An evolutionary theory of economic change. Cambridge MA Belknap (Vol. 93). Cambridge: Harvard University Press. 1982.

Neto, J. , \& Da Silva, C. Experiências em Gestão do Conhecimento na Rede Petrogas Sergipe. Aracaju. 2012.

Neuman, M., et al. Plan Estratégico para el Desarrollo de Proveedores de Bienes y Servicios de la Industria del Gas y del Petróleo. Universidad Nacional de General Sarmiento. Buenos Aires. Ministerio de Industria. 2012.

Ortega Rangel; R. "Aprendizaje tecnológico y acumulación de capacidades en un grupo del sector siderúrgico". Innovar. Vol. 15. N2 25. Universidad Nacional de Colombia. Bogotá. pp. 90-102, ene-jun 2005.

Pavitt, K. "Sectorial patterns of technical change: towards a taxonomy and theory". Reserach policy 13 (6). p. 343-373, 1984..

Pietrobelli, C., y Rabellotti, R. Upgrading in Clusters and Value Chains in Latin America The Role of Policies. Washington, D. C. BID. 2004.

Poma, L. "La nueva competencia territorial”. En Boscherini, F. y Poma, L. (Comps.) Territorio, conocimiento y competitividad de las empresas. El rol de las instituciones en el espacio global. Buenos Aires. Miño y Dávila. 2000.

Schumpeter, J "The Explanation of the Business Cycle". Económica. dic. p. 290-299, 1972.

Schumpeter, J. Teoría del desenvolvimiento económico. Fondo de Cultura Económica. México 1997.

Scherer, E. "The knowledge network: knowledge generation during implementation of aplication software packages". Logistic Information Management. 13 (4) p. 210-218, 2000.

Soete, L. et al. Systems of Innovation. UNU-MERIT, Vol. 62. United Nations University. Maastricht, 2009.

Teece, D., \& Pisano, G. The dynamic capabilities of firms: an introduction. Industrial and Corporate Change, Harvard University, 3(3), Boston, p. 537-556, 1994.

Torres, O. "The SME concept of Pierre-André Julien: an analysis in terms of proximity". Piccola Impresa/Small Business. Universidad Montpellier, p. 1-12, 2004. 
Tudela Villalonga, L. y Garrido, C. "Gestión de PyMes innovadoras. Agrupamientos productivos". En C. Garrido y N. Rondero López (Coordinadores) Encuentro de saberes. Universidad-Empresa para la Innovación. Volumen IV. RedUniversidad Empresa ALCUE. Unión de Universidades de América Latina UDAL. México. 2015.

Yoguel, G. "Creación de competencias en ambientes locales y redes productivas". Revista de la CEPAL № 71 . Santiago de Chile. ago. p. 71101, 2000.

Yoguel, G. y Boscherini, F. "El desarrollo de las capacidades innovativas de las firmas y el rol del sistema territorial”. Desarrollo Económico № 161. Buenos Aires. . p. 32-70, 2001.

Yoguel, G. et al; La política científica y tecnológica argentina en las últimas décadas: perspectiva del desarrollo de proceso de aprendizaje, CEPAL. S. de Chile, 2007.

Susana Graciela Landriscini. Lic. en Economía. IPEHCS CONICET UNCo. Argentina. Docente Investigador Facultad de Economía y Administración. Universidad Nacional del Comahue. Buenos Aires 1400. Neuquén. Argentina. gslandriscini@speedy.com.ar

Osvaldo Preiss. Mg. en Economía. Docente investigador. Facultad de Economía y Administración. Universidad Nacional del Comahue. Buenos Aires 1400 Neuquén. osvaldopreiss@yahoo.com.ar

Lisandro Robles. Contador Público Nacional. Maestrando en Economía y Desarrollo Industrial Mención PYMES. Universidad Nacional de General Sarmiento. UNComahue. Buenos Aires 1400. lilo.neuquen@gmail.com

Líneas de investigación de los autores: Proyecto E/100"Dinámica productiva y economía urbana. Neuquén y su entorno. Trayectorias, evidencias y perspectivas de desarrollo". (2014/2017). Facultad de Economía y Administración. Universidad Nacional del Comahue, y Proyecto PICT "Recursos naturales y territorialidades en la Argentina Contemporánea". ANPCYT/UNS/UNComahue/UNRío Cuarto/UNSan Juan. Argentina. 


\section{Anexo}

Cuestionario aplicado a las pequeñas y medianas empresas proveedoras de la cadena de los hidrocarburos en la Cuenca Neuquina

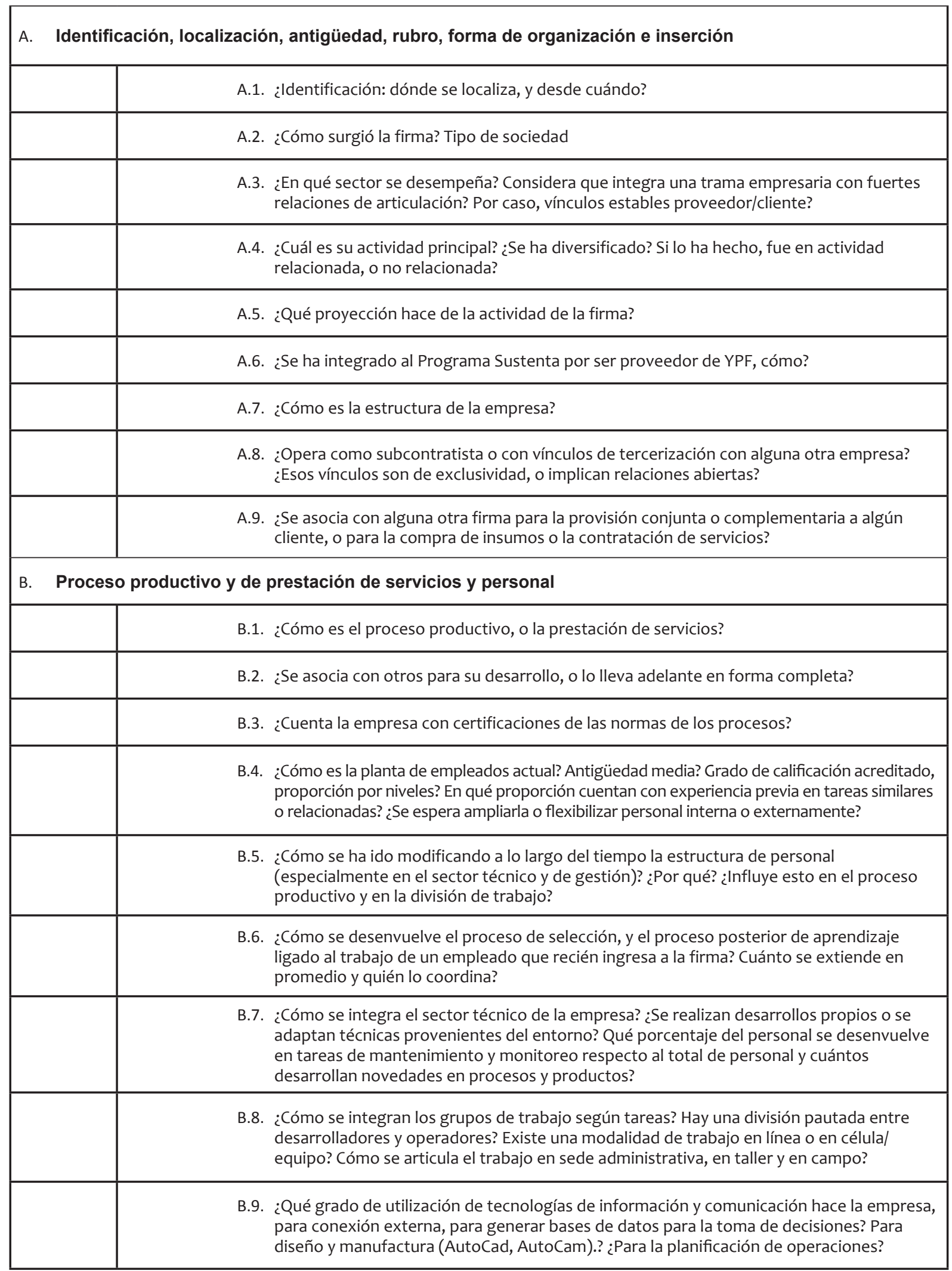




\begin{tabular}{|c|c|}
\hline & $\begin{array}{c}\text { B.10.¿Dispone la firma de intranet? La usan sus empleados para el desarrollo de sus tareas? } \\
\text { Usa el personal de la firma Internet, email, sitios técnicos on line, nube, etc, para ejecutar } \\
\text { su trabajo, simulaciones o controlar procesos? Usan medios informáticos para facilitar el } \\
\text { acceso a capacitación a distancia? }\end{array}$ \\
\hline & $\begin{array}{c}\text { B.11.¿Desarrolla la firma actividades de capacitación internas ligadas al trabajo o externas para } \\
\text { el personal? Es la capacitación general o específica por tarea? }\end{array}$ \\
\hline $\begin{array}{c}\text { B.12. Cómo se resuelve el tema del uso del tiempo entre la jornada laboral y los horarios de la } \\
\text { capacitación? }\end{array}$ \\
\hline B.13.¿Cuál es el capital más importante de su empresa? \\
\hline $\begin{array}{c}\text { B.14.¿Mejoró el desempeño de los empleados en el último año? ¿Introdujeron mejoras } \\
\text { menores o significativas sobre el proceso? ¿Proponen nuevas ideas? }\end{array}$ \\
\hline B.15.¿Cómo resuelve la organización la transformación del nuevo conocimiento adquirido por \\
un empleado, en un procedimiento aplicable por el resto?
\end{tabular}

\section{La información y el conocimiento; gestión y toma de decisiones}

\begin{tabular}{|c|c|}
\hline & $\begin{array}{l}\text { C.1. ¿Qué tipo de información es considerada más importante para la organización la interna o } \\
\text { la externa a la firma? }\end{array}$ \\
\hline & $\begin{array}{l}\text { C.2. Está instalada la formalización del registro de información por áreas?, ¿Se cruza la } \\
\text { información producida para la toma de decisiones? }\end{array}$ \\
\hline & $\begin{array}{l}\text { C.3. Cómo se fijan prioridades en la construcción de información: a partir de lo tecnológico, } \\
\text { lo administrativo, lo económico-financiero, de mercados, de proveedores)? ¿Qué } \\
\text { sector se encarga de obtenerla y cómo lo hace (de qué fuentes: cámaras empresarias, } \\
\text { proveedores, clientes, otros empresarios, etc. -)? }\end{array}$ \\
\hline & $\begin{array}{l}\text { C.4. ¿Se cuenta con personal específico para la gestión de información? ¿Cuenta la empresa } \\
\text { con desarrollos de software específicos aplicados al perfil de la actividad y de la empresa? }\end{array}$ \\
\hline & $\begin{array}{l}\text { C.5. ¿Cómo procesan y almacenan la información? ¿La sistematizan en bases de datos? ¿Cómo } \\
\text { es el acceso a dichas bases para la identificación, tipificación y resolución de problemas? }\end{array}$ \\
\hline & $\begin{array}{l}\text { C.6. ¿Qué sector y qué nivel se encarga de la toma de decisiones, según la complejidad o el } \\
\text { alcance de los problemas? ¿Cómo usa la información para ello? }\end{array}$ \\
\hline & $\begin{array}{l}\text { C.7. ¿Recibe asesoría interna y/o externa en materia de información? En qué áreas es más } \\
\text { frecuente recurrir a consultores externos? Por qué vías se contrata? }\end{array}$ \\
\hline & $\begin{array}{l}\text { C.8. ¿Cómo planifica la empresa sus actividades, si es que lo hace? Realiza evaluación de } \\
\text { marcha y de resultados por sector? }\end{array}$ \\
\hline \multicolumn{2}{|c|}{ D. Relación con el entorno } \\
\hline & $\begin{array}{l}\text { D.1. ¿Cuál es la relación más relevante continua que mantiene hacia afuera la empresa en el } \\
\text { desarrollo de su actividad? Se trata de relaciones de complementariedad, de cooperación, } \\
\text { o de acoplamiento asimétrico con otras empresas? Integra un cluster o red de empresa? }\end{array}$ \\
\hline & $\begin{array}{l}\text { D.2. ¿Tienen la empresa relación con alguna institución tecnológica (INVAP, INTI, Sustenta, } \\
\text { Y-Tec, UNCo)? ¿En qué consiste? Es estable? O puntual para resolver un problema } \\
\text { específico, un diseño o un servicio? }\end{array}$ \\
\hline & D.3. ¿Integra alguna cámara empresaria? ¿Qué actividades comparte en ese nivel? \\
\hline & $\begin{array}{l}\text { D.4. ¿Evalúan sus prácticas en relación con las de sus competidores?, Puede señalar cómo } \\
\text { califica el grado de eficiencia productiva y de servicios de la empresa en relación con los } \\
\text { desarrollos sectoriales actuales a nivel internacional, y con las mejores prácticas internas? }\end{array}$ \\
\hline & $\begin{array}{l}\text { D.5. ¿Considera que las firmas que operan en los yacimientos, acorde al nuevo sistema } \\
\text { técnico de fracturas horizontales, y de operaciones múltiples coordinadas just in time } \\
\text { como un proceso industrial, adquieren conocimientos estratégicos que las posicionan } \\
\text { favorablemente en los nuevos tiempos del sector de los hidrocarburos? Es posible afirmar } \\
\text { que los empleados aprenden en las relaciones que mantienen con el personal de otras } \\
\text { empresas en los yacimientos, particularmente en los no convencionales? }\end{array}$ \\
\hline
\end{tabular}

